\title{
Darwinian Selection Discriminates Young Athletes: the Relative Age Effect in Relation to Sporting Performance
}

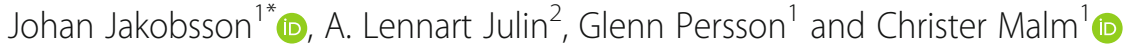

\begin{abstract}
Background: The relative age effect (RAE) is a worldwide phenomenon, allowing sport participation and elite selection to be based on birthdate distribution. Negative consequences include both a narrow, non-optimal elite selection and negative health effects on entire populations. This study investigated the RAE and athletic performance in multiple individual sports in Sweden.

Methods: Birthdates of athletes born between the years 1922 and 2015 were collected across 4-month periods (tertiles: T1, T2, T3) from cross-country skiing $(N=136,387)$, orienteering $(N=41,164)$, athletics $(N=14,503)$, alpine skiing ( $N=508)$, E-sports $(N=47,030)$, and chess $(N=4889)$. In total, data from 244,560 athletes (women: $N=79$, 807, men: $N=164,753$ ) was compared to the complete parent population of 5,390,954 births in Sweden during the same years. Chi-squared statistics compared parent and cohort distributions stratified by sport, sex, and age.

Results: A significantly skewed distribution of birthdates was present in all sports, both sexes, and most age groups. The largest RAEs are seen in children where T1 often constitutes $40-50 \%$ and T3, 20-25\% of the population. In E-sports, an inversed RAE was seen in adults. In most investigated sports, birthdate distribution was correlated to performance in children but not in adults.

Conclusions: Skewed birthdate distributions were consistently prevalent in all investigated individual sports in Sweden, both physically demanding and cognitive/skill-based. As sport participation is related to total level of physical activity, both present and future, failing to address the RAE issue at an early age will result not only in a narrow and arbitrary selection for adult elite athletes but also in a negative impact on public health.
\end{abstract}

Keywords: Relative age effect, Sports, Participation, Youth, Athletes, Health

\section{Key Points}

- The relative age effect is consistently prevalent in most individual sports in Sweden, both physically demanding and cognitive/skill-based.

- In most sports, earlier born children perform better and are higher ranked than later-born peers, a trend

\footnotetext{
* Correspondence: Johan.jakobsson@umu.se

'Section for Sports Medicine, Department of Community Medicine and Rehabilitation, Umeå University, Gösta Skoglunds väg 3, SE-901 87 Umeå, Sweden

Full list of author information is available at the end of the article
}

not seen in adult athletes where there is no clear correlation between birth date and performance.

- Failing to address the relative age issue at an early age will result not only in a narrow, arbitrary, selection for adult elite athletes, but also in a negative impact on public health.

\section{Introduction}

Selection of future athletes at a young age favors birthdates early in the season, creating a skewed distribution also among adult elite athletes in team sports [1] - the relative age effect (RAE). Human development related to date of birth was described already in the 1920s [2] and

\section{Springer Open}

(๑) The Author(s). 2021 Open Access This article is licensed under a Creative Commons Attribution 4.0 International License, which permits use, sharing, adaptation, distribution and reproduction in any medium or format, as long as you give appropriate credit to the original author(s) and the source, provide a link to the Creative Commons licence, and indicate if changes were made. The images or other third party material in this article are included in the article's Creative Commons licence, unless indicated otherwise in a credit line to the material. If material is not included in the article's Creative Commons licence and your intended use is not permitted by statutory regulation or exceeds the permitted use, you will need to obtain permission directly from the copyright holder. To view a copy of this licence, visit http://creativecommons.org/licenses/by/4.0/. 
further described in the 1930s [3]. Later, RAE was described in the context of academic performance [4] and mental illness [5]. In 1982, "The unknown exclusion in sports" published in "Athletics" (Swedish) first revealed the RAE in sports [6]. Today, RAE is a well-known and worldwide phenomenon, influencing the acquisition of young athletes for future elite performance [7], but children with elite-level ambition and potential, born late in the season, have an unjustified lower chance of sport participation past puberty [8].

Relative age effects are apparent across multiple sports, including ice hockey [9-11], soccer [12-14], baseball [15], basketball [13, 16], American football [17], rugby $[18,19]$, handball [20], swimming [21], and tennis [22]. In gymnastics [23] and athletics [24], reversed RAEs have been described. Further, RAEs are prevalent across all age groups from children to adults, and all skill levels [19]. In team sports, RAEs are unanimous across countries and persists into adult elite squads [14, 25], such as in males drafted for the NHL 2000-2005 [26] and in 1997-2007 FIFA U17 World Cup players, where 40\% were born in the first, and only $16 \%$ in the last, quarter of the year [27]. Significant RAEs in male professional soccer players were also found in Italy [28], Germany, Japan, Brazil, and Australia [29]. While common, some argue that RAEs are not always present, especially not in women's sports [30].

When present on a larger scale, negative health effects of early selection in sports are inevitable, as an unhealthy chain of events is initiated: As an increasing proportion of physical activity takes place in organized forms [31], lack of sport participation, as a result of RAE selection when young, will thus reduce the lifetime levels of physical activity [32] and subsequently increase the risk of inactivity-related diseases.

Another problematic issue of biased selection in sports is the violation of the guiding principles by the United Nations Convention on the Rights of the Child (CRC) [33]. Here, Article 2 states the equal value of all children and that every child has the right to participate. Further, Article 3 states that all decisions concerning a child should be made in the best interest of the child. As of January 1, 2020, CRC is legally binding in Sweden [34].

To ensure fair and equal competition, youth sports are generally organized into age groups by date of birth [14, 35], ranging over a 1- to 2-year period with cut-off times differing between sports and countries [14, 36]. This organization, with a full 2-year age difference within the same age group, and even more in biological maturation, is one aspect of the RAE $[7,14]$. Other social agents, further described by Hancock, Adler [37], have also been proposed to have large influences on RAEs. Age-group division benefits relatively older athletes, while increasing the risk of injury and early dropout from sports among children born later in the season $[7,18,38]$. The highest RAE prevalence is found in team sports [35], but exists also in individual sports such as alpine skiing and Nordic combined [39], swimming [40], master swimming and athletics [41], shooting [42], ski jumping, and snowboarding [39]. Sports with high physical, rather than technical demands are more often affected [25, 43].

Our understanding of RAEs in individual sports is limited, and previous findings need validation by studies with adequate sample size [39]. Published studies have rarely considered the parental population birthdate distribution $[13,35,39,40]$ but assumed equal distribution (25\% per quarter and $0.083 \%$ per month) $[39,44]$, sometimes including the day-corrected statistic [45]. Using the parental population as comparison is key in chisquared tests [46], else the Type 1 error is not controlled for and the goodness-of-fit test biased.

The purpose of the present study was twofold: (1) to examine the RAE in individual sports, including both physically demanding (cross-country skiing, alpine skiing, athletics, orienteering) and cognitive/skill-based (E-sports and chess) sports and (2) to investigate the relationship between RAE and performance.

\section{Method \\ Procedure}

Birthdate data was collected from official websites or provided by the corresponding sport's federation. Crosscountry skiing data was retrieved from three different datasets: From the page of FIS (http://fisski.com) and the Swedish Ski Federation (http://skidor.com) and kindly provided by Johan Nyman at http://skidresultat.se. The three datasets contain both overlapping and unique data and were therefore not merged but analyzed separately (Table 1). Alpine skiing data was retrieved from FIS (http://fisski.com), and athletics data was provided by Bo Nordin and A. Lennart Julin, retrieved from an internal database of Swedish athletics results. These results include the annual best performance (top 20 to 30, depending on year and event) for all age groups. Orienteering data was retrieved from the Swedish Orienteering federation (http://www.svenskorientering.se/), Chess data from the Swedish Chess Federation (https:// schack.se/), and E-sports data from Swedish Gaming Association (https://sverok.se/). Athletes whose birthdates were not declared by the dataset were excluded from the study. Duplicates were removed (participation in more than one age group or event) leaving us with a total of 244,558 individuals.

\section{Data collection}

Birthdates were summarized across 4-month periods (hereafter called tertiles, T) as described in Table 1. Subsequently, tertile one (T1) includes athletes with 
Table 1 Data overview

\begin{tabular}{|c|c|c|c|c|c|c|}
\hline Sport & Data retrieved & Age & Age range & Total $N$ & Females & Males \\
\hline Cross-country skiing $^{a}$ & 2014 & $33.6 \pm 19.8$ & $1-90$ & 124,139 & 50,684 & 73,381 \\
\hline Cross-country skiing $^{b}$ & 2015 & $34.9 \pm 17.2$ & $4-90$ & 11,377 & 2596 & 8781 \\
\hline Cross-country skiing ${ }^{c}$ & 2015 & $21.6 \pm 4.5$ & $17-39$ & 943 & 361 & 582 \\
\hline Alpine Skiers & 2015 & $18.9 \pm 3.2$ & $17-39$ & 502 & 244 & 258 \\
\hline Athletics & 2019 & $21.8 \pm 9.8$ & $10-68$ & 14,503 & 7511 & 6992 \\
\hline Orienteering & 2015 & $34.7 \pm 21.2$ & $1-95$ & 41,164 & 16,925 & 24,239 \\
\hline Chess & 2016 & $41.4 \pm 22.3$ & $5-95$ & 4900 & 327 & 4562 \\
\hline E-Sport & 2016 & $21.7 \pm 5.2$ & $10-45$ & 47,030 & 1159 & 45,871 \\
\hline All athletes & - & $31.0 \pm 18.5$ & $1-95$ & 244,558 & 79,807 & 164,666 \\
\hline Reference population & 2016 & - & - & $5,390,954$ & $2,618,818$ & $2,772,136$ \\
\hline
\end{tabular}

${ }^{a}$ Dataset retrieved from the official timing system for Swedish Skiing "SSF-Timing" and includes recreational, competitive, and elite skiers entered in one or more competitions sanctioned by the Swedish Ski Association

${ }^{b}$ Dataset retrieved from www.skidresultat.se, and includes recreational, competitive, and elite skiers finishing one or more races

'Dataset of FIS-registered (elite) cross-country skiers. In total, the sex of 74 subjects was unspecified. Reference population refers to all births in Sweden between the years 1961 and 2011

birthdates from January 1st to April 28th (or 29th), tertile two (T2) from May 1st to August 31st, and tertile three (T3) from September 1st to December 31st. Age distribution summarized in Table 2. We chose to divide the year into tertiles instead of the more common quarters, as both divisions are arbitrarily time-periods, with tertiles giving higher statistical power.

As a reference parent population, the complete record of all Swedish births between the years 1961 and 2011 was retrieved from Statistics Sweden (https://www.scb. se/) and used for all chi-squared analyses, with exact adjustment for each single analysis. In the reference parent population, birth distributions were $\mathrm{T} 1=35.1 \%, \mathrm{~T} 2=$ $34.5 \%$, and $\mathrm{T} 3=30.4 \%$ (Supplementary file 1 ). For analyses including individuals mainly or only born earlier than 1961, the birth distribution of 1961-1970 was assumed $(\mathrm{T} 1=35.4 \%, \mathrm{~T} 2=33.6 \%, \mathrm{~T} 3=31 \%)$.

\section{Stratified Analyses}

Analyses were executed for the whole sample and divided into age groups' sport type (physical and skillbased sports). To determine the effect of age on RAEs, samples were categorized into children ( $\leq 10$ years),

Table 2 Age distribution of whole athlete population

\begin{tabular}{ll}
\hline Age & $\boldsymbol{N}$ \\
\hline$\leq 6$ & 3528 \\
$7-8$ & 7336 \\
$9-10$ & 11,125 \\
$11-15$ & 33,267 \\
$16-20$ & 41,316 \\
$21-39$ & 66,230 \\
$\geq 40$ & 81,756 \\
\hline
\end{tabular}

young adolescent (11-15 years), adolescents (16-20 years), adults (21-39 years), and masters ( 40 years and older). Where applicable $(N \geq 70)$, further sub-division were made including $\leq 6$ years, $7-8$ years, $9-10$ years, $40-59$ years, and $\geq 60$ years. Data was sub-analyzed by sport (three different datasets covering cross-country skiing) and sex. For athletics, data includes athletes competing in the age groups from 14 years and older and seen as juniors until 23 years of age. Thus, for athletics, age groups were 14-17 years, 18-22 years, and 23 years and older. For all sports, except athletics, sub-disciplines (i.e., skiing, or orienteering distance, alpine discipline) are not specified. For athletics, sub-analyses are executed for each event, and by sex and age when adequate. When not specified, all events are included in the "athletics" analysis.

When available, ranking (orienteering), rating, (crosscountry skiing dataset 2 and chess), and performance (athletics) data were analyzed as well.

\section{Statistical Analysis}

A cut-off date on Jan 1st was used, which is the standard procedure in all Swedish sports. Chi-squared tests assessed differences in frequency counts between tertiles. Estimated distribution with $95 \%$ confidence interval (CI) is reported. The parent population distribution was set as hypothesized probability, adjusted for each chisquared analysis. Cramer's $V(V)$ is calculated as the effect size (ES) and interpreted as a small (0.07), medium (0.21), or large effect (0.35) [47]. Distribution analyses were not executed on sub-divided samples (i.e., a certain age group and/or sex in a certain sport/event) with less than 70 individuals. Because the parental population (expected) distribution is known, the ratio between expected and observed distributions (hereinafter called 
ratio) is expressed in all figures for visualization purposes. Because the parent distribution (full population) is rarely known, it is common to use odds ratio (OR). We chose to use the expected (true) versus observed distribution ratio, as we indeed had the full, parental dataset of the population. Also, compared to OR this ratio is easier to understand by the non-statistician.

Rating data (i.e., higher is better in cross-country skiing and chess) and ranking data (i.e., lower is better in orienteering) were analyzed using the non-parametric Kruskal-Wallis one-way analysis of variance test with the Steel-Dwass method for post-hoc comparisons. Performance data (athletics) was analyzed using one-way analysis of variance (ANOVA), with Tukey's honest significant difference test for post-hoc comparisons. Mean and standard deviation were used for parametric descriptive statistics, and median with interquartile range (IQR) for non-parametric data. All calculations were made in JMP 15.1 (SAS Institute, USA) and statistical significance set at $P \leq 0.05$.

\section{Results}

In all investigated sports both sexes show significantly skewed birthdate distribution, starting at age groups 6 years and younger.

Due to a large amount of data, results are herein summarized. Complete statistical data can be found in supplementary materials: reference population raw data (Supplementary file 1), distribution analyses with chisquared statistics (2), expected to observed distribution ratios (3), performance and rating/ranking (4), and raw data for all athlete datasets (5).

\section{Distribution of Birthdates Among Athletes: Summarized}

Table 3 shows the distribution statistics for all sports and ages pooled, analyzed by sport. Here, RAEs are evident in the whole population of athletes and in physical sports alone, while in skill-based sports, this is true for males but not females. Table 4 shows the distribution of athletes sub-analyzed by sport, and for two specific events in athletics. Table 5 shows the distribution analyzed by age group and sex of the whole sample. Relative age effects are present in all age groups except for males in the age of 21-39 years, and adults over the age of 40 years. Figures 1, 2, 3, 4, 5, 6 and 7 show the tertile distribution, expressed as the ratio between true and observed frequencies, in analyzed sports and age groups. Details for sub-analyses by sex, age group, sport, and event are found in supplementary file 2 .

Stratified by sport (Table 4), RAEs are present in all sports except elite alpine skiing, female E-sports, and chess. However, in E-sporting males, the RAE is inversed in some age groups (21-39) while an ordinary RAE is seen in some (Fig. 6). Regarding age, the magnitude of skewness decreases with higher age, seen in Table 5 and Figs. 1, 2, 3, 4, 5, 6 and 7. Summarized in Fig. 1, RAEs are highly prevalent in young athletes in orienteering, cross-country skiing, chess, and E-sports.

\section{Distribution of Athletes: By Dataset}

As seen in Fig. 2, cross-country skiing ${ }^{1}(N=124$ 139) shows significant RAEs in all age groups, ranging from $\leq 6$ to $21-39$ years. Effect sizes are largest in the youngest athletes $(\leq 6$ years, $V=0.31)$ and decrease with higher age ( $\geq 40$ years, $V=0.07)$. Stratified by sex, RAEs exist in all age groups ranging from $\leq 6$ to $21-39(P<$ $0.05)$ except for $11-15$-year-old girls $(P=0.200, V=0.1$, ratio $\left._{\mathrm{T} 1}=1.03\right)$.

In Fig. 3, data on cross-country skiing ${ }^{2}(N=11377)$ is shown, where RAEs are present in both sexes in athletes up to 40 years of age. The most skewed distribution in the whole population was found in boys up to 8 years with $51 \%$ (ratio $=1.53), 29 \%(0.82)$ and $20 \%(0.64)$ of the athletes born in $\mathrm{T} 1, \mathrm{~T} 2$, and $\mathrm{T} 3$, respectively

Table 3 Distribution and summary statistics for the whole athlete population and by sport type

\begin{tabular}{|c|c|c|c|c|c|c|c|c|c|c|c|}
\hline \multirow[t]{2}{*}{ Sport } & \multirow[t]{2}{*}{ Sex } & \multicolumn{2}{|c|}{ Chi-squared statistics } & \multicolumn{4}{|c|}{ Absolute distribution $(N)$} & \multicolumn{3}{|c|}{ Relative distribution (\%) $(95 \% \mathrm{Cl})$} & \multirow[b]{2}{*}{$V$} \\
\hline & & $x^{2}$ & $P$ value & Total & T1 & $\mathrm{T} 2$ & T3 & $\mathrm{T1}$ & $\mathrm{T} 2$ & T3 & \\
\hline \multirow[t]{3}{*}{ All } & Both & 205.0 & $<0.001$ & 244558 & 89036 & 83781 & 71741 & $36.4(36.2-36.6)$ & $34.3(34.1-34.4)$ & $29.3(29.2-29.5)$ & 0.12 \\
\hline & Male & 61.1 & $<0.001$ & 164666 & 59269 & 56492 & 48905 & $36.0(35.8-36.2)$ & $34.3(34.1-34.4)$ & $29.7(29.5-29.9)$ & 0.10 \\
\hline & Female & 192.9 & $<0.001$ & 80077 & 29752 & 27521 & 22804 & $37.3(36.9-37.6)$ & $34.1(33.8-34.5)$ & $28.6(28.3-28.9)$ & 0.16 \\
\hline \multirow[t]{3}{*}{ Physical } & Both & 2127.0 & $<0.001$ & 192628 & 71052 & 65965 & 55611 & $36.9(36.7-37.1)$ & $34.3(34.0-34.5)$ & $28.9(28.7-29.1)$ & 0.23 \\
\hline & Male & 135.0 & $<0.001$ & 114233 & 41827 & 39173 & 33233 & $36.6(36.3-36.9)$ & $34.3(34.0-34.6)$ & $29.1(28.9-29.4)$ & 0.13 \\
\hline & Female & 194.4 & $<0.001$ & 78321 & 29212 & 26760 & 22349 & $37.3(37.0-37.6)$ & $34.2(33.8-34.5)$ & $28.5(28.2-28.9)$ & 0.16 \\
\hline \multirow[t]{3}{*}{ Skill } & Both & 12.7 & 0.002 & 51930 & 17984 & 17816 & 16130 & $34.6(34.2-35.0)$ & $34.3(33.9-34.7)$ & $31.1(30.7-31.5)$ & 0.09 \\
\hline & Male & 13.2 & 0.001 & 50433 & 17442 & 17319 & 15672 & $34.6(34.2-35.0)$ & $34.3(33.9-34.8)$ & $31.1(30.7-31.5)$ & 0.09 \\
\hline & Female & 1.6 & 0.442 & 1486 & 540 & 491 & 455 & $36.3(34.0-38.8)$ & $33.0(30.7-35.5)$ & $30.6(28.3-33.0)$ & 0.13 \\
\hline
\end{tabular}

$X^{2}$ chi-squared statistic, $T$ tertile, $V$ effect size, Cramer's $V$

Parent population (national birth statistics) was set at expected distribution in chi-squared test

"Physical" includes Cross-country skiing, athletics, orienteering and alpine skiing. "Skill" includes E-sports and chess 
Table 4 Distribution and statistics summary by sport and selected athletic events

\begin{tabular}{|c|c|c|c|c|c|c|c|c|c|c|c|}
\hline \multirow[t]{2}{*}{ Sport } & \multirow[t]{2}{*}{ Sex } & \multicolumn{2}{|c|}{ Chi-squared statistics } & \multicolumn{4}{|c|}{ Absolute distribution $(N)$} & \multicolumn{3}{|c|}{ Relative distribution (\%) $(95 \% \mathrm{Cl})$} & \multirow[b]{2}{*}{$v$} \\
\hline & & $\overline{x^{2}}$ & $P$ value & Total & T1 & T2 & T3 & $\overline{\mathrm{T} 1}$ & T2 & T3 & \\
\hline \multirow[t]{2}{*}{ Cross-country skiing $^{a}$} & Male & 47.0 & $<0.001$ & 73381 & 26521 & 25330 & 21530 & $36.1(35.8-36.5)$ & $34.5(34.2-34.9)$ & $29.3(29.0-29.7)$ & 0.11 \\
\hline & Female & 61.2 & $<0.001$ & 50684 & 18571 & 17369 & 14744 & $36.6(36.2-37.1)$ & $34.3(33.9-34.7)$ & $29.1(28.7-29.5)$ & 0.13 \\
\hline \multirow[t]{2}{*}{ Cross-country skiing ${ }^{b}$} & Male & 23.2 & $<0.001$ & 8781 & 3297 & 2948 & 2536 & $37.5(36.5-38.6)$ & $33.6(32.6-34.6)$ & $28.9(27.9-29.8$ & 0.16 \\
\hline & Female & 41.9 & $<0.001$ & 2596 & 1055 & 875 & 666 & $40.6(38.8-42.5)$ & $33.7(31.9-35.5)$ & $25.7(24.0-27.4)$ & 0.25 \\
\hline \multirow[t]{2}{*}{ Cross-country skiing $^{c}$} & Male & 14.4 & 0.007 & 582 & 243 & 202 & 137 & $41.7(37.7-45.7)$ & $34.8(31.1-38.8)$ & $23.5(20.2-27.1)$ & 0.28 \\
\hline & Female & 8.9 & 0.012 & 361 & 153 & 120 & 88 & $42.5(37.6-47.7)$ & $33.1(28.5-38.2)$ & $24.3(20.2-29.0)$ & 0.28 \\
\hline \multirow[t]{2}{*}{ All athletics events } & Male & 136.3 & $<0.001$ & 6992 & 2861 & 2387 & 1744 & $40.9(39.8-42.1)$ & $34.1(33.0-35.3)$ & $24.9(23.9-26.0)$ & 0.26 \\
\hline & Female & 145.1 & $<0.001$ & 7511 & 3108 & 2494 & 909 & $41.4(40.3-42.5)$ & $33.2(32.1-34.3)$ & $25.4(24.4-26.4)$ & 0.26 \\
\hline \multirow[t]{2}{*}{ Athletics 100 m } & Male & 81.8 & $<0.001$ & 1266 & 584 & 416 & 266 & $46.1(43.4-48.9)$ & $32.9(30.3-35.5)$ & $21.0(18.9-23.3)$ & 0.36 \\
\hline & Female & 55.1 & $<0.001$ & 976 & 444 & 320 & 212 & $45.5(42.4-48.6)$ & $32.8(29.9-35.8)$ & $21.7(19.2-24.4)$ & 0.34 \\
\hline \multirow[t]{2}{*}{ Athletics discus } & Male & 28.5 & $<0.001$ & 664 & 271 & 252 & 141 & $40.8(37.1-44.6)$ & $38.0(34.3-41.7)$ & $21.2(18.3-24.5)$ & 0.32 \\
\hline & Female & 19.7 & $<0.001$ & 714 & 303 & 237 & 174 & $42.4(38.9-46.1)$ & $33.2(29.8-36.7)$ & $24.4(21.4-27.7)$ & 0.29 \\
\hline \multirow[t]{2}{*}{ Orienteering } & Male & 15.8 & $<0.001$ & 24239 & 8806 & 8226 & 7207 & $36.3(35.7-36.9)$ & $33.9(33.3-34.5)$ & $29.7(29.2-30.3)$ & 0.11 \\
\hline & Female & 28.0 & $<0.001$ & 16925 & 6231 & 5824 & 4870 & $36.8(36.1-37.6)$ & $34.4(33.7-35.1)$ & $28.8(28.1-29.5)$ & 0.14 \\
\hline \multirow[t]{2}{*}{ Alpine skiing } & Male & 2.0 & 0.367 & 258 & 99 & 80 & 79 & $38.1(32.7-44.4)$ & $31.0(25.7-36.9)$ & $30.6(25.3-36.5)$ & 0.21 \\
\hline & Female & 1.4 & 0.491 & 244 & 94 & 78 & 72 & $38.5(32.6-44.8)$ & $32.0(26.4-38.1)$ & $29.5(24.2-35.5)$ & 0.20 \\
\hline \multirow[t]{2}{*}{ E-Sport } & Male & 11.4 & $0.003^{d}$ & 45871 & 15793 & 15848 & 14230 & $34.4(34.0-34.9)$ & $34.5(34.1-34.9)$ & $31.0(30.6-34.0)$ & 0.09 \\
\hline & Female & 2.0 & 0.373 & 1159 & 421 & 382 & 356 & $36.3(33.6-39.1)$ & $33.0(30.3-35.7)$ & $30.7(28.1-33.4)$ & 0.14 \\
\hline \multirow[t]{2}{*}{ Chess } & Male & 10.8 & 0.005 & 4562 & 1649 & 1471 & 1442 & $36.1(34.8-37.6)$ & $32.2(30.9-33.6)$ & $31.6(30.3-33.0)$ & 0.16 \\
\hline & Female & 0.3 & 0.86 & 327 & 119 & 109 & 99 & $36.4(31.4-41.8)$ & $33.3(28.4-38.6)$ & $30.3(25.6-35.5)$ & 0.12 \\
\hline
\end{tabular}

$\boldsymbol{X}^{2}$ chi-squared statistic, $V$ effect size, Cramer's $V$

Parent population (national birth statistics) was set at expected distribution in chi-squared test

aDatabase retrieved from "SSF-Timing" and includes recreational, competitive and elite skiers

${ }^{b}$ Data retrieved from www.skidresultat.se, and includes recreational, competitive and elite skiers

'Dataset of FIS-registered (elite) cross-country skiers

Inversed RAE

(Supplements 2 and 3). As seen in Fig. 3, the skewed distribution becomes less evident in older age groups. The effect size was medium $(\leq 0.21 \mathrm{~V}<0.35)$ for all age groups up to $21-39$ years and small $(V=0.07)$ for $\leq 40$ years. Here, a skewed distribution was evident in 11-15year-old girls $\left(P=<0.001, V=0.29\right.$, ratio $\left.{ }_{\mathrm{T} 1}=1.18\right)$, which differs from cross-country skiing ${ }^{1}$.

In elite cross-country skiers (Fig. 4), a skewed distribution was found in both junior and senior athletes (Fig. 4) with medium effect sizes $(V=0.26$ and 0.31 , respectively). When sub-analyzed by sex, significance remained only for male seniors (Supplement 2). In elite alpine skiers, no significant RAE was found, neither in junior athletes nor in senior athletes. A sub-analysis by sex shows a significant RAE in adult males, but with limited sample size $(N=70)$.

In athletics (Fig. 4), RAEs were seen in young adolescents (14-17 years, $V=0.33$ ) and adults (23 years and older, $V=0.18)$ but not older adolescents (18-22 years, $V$ $=0.16$ ) when analyzed by age groups (Fig. 4). For athletics, RAEs were consistently evident in both sexes. The most skewed distribution when analyzed by age group was found in 14-year-old boys with 51\% (1.3), 33\% (0.98), and $16 \%(0.68)$ of the population in T1, T2, and T3, respectively $(V=0.45)$, with similar distribution for girls, $48 \%$ (1.24), 33\% (0.97), and 19\% (0.76), respectively $(V=0.41)$.

Sub-stratified by specific events, the most skewed distributions and largest effect sizes were found in 60 $\mathrm{m}$ (children/young adolescents), $100 \mathrm{~m}, 400 \mathrm{~m}$, high jump, and pole vault while the distribution is not skewed in long-distance running with mainly adult competitors $(3000 \mathrm{~m}-42.2 \mathrm{~km})$. Further, no significant RAE was found in shot put $(N=216)$ or 60 -m hurdles $(N=156)$. For additional details on athletic events, see Supplement 2.

In orienteering (Fig. 5), RAEs were found in age groups $\leq 8,11-15,16-20,21-39,40-59$, and $\leq 60$ years, with $V=$ $0.25,0.19,0.11,0.17,0.06,0.13$, and 0.16 , respectively. Significant RAEs were evident in all age groups including boys and girls up to 5 years of age $(P<0.001, V=0.37)$. In adults over 60 years, while the distribution is near equal $(\approx 33 \%$ per tertile), an inversed RAE is evident in both sexes $(P<0.05, V=0.14$, ratio T3 $=1.06$, for males; $P<$ $0.05, V=0.19$, ratio $\mathrm{T} 3=1.09$ for females) because the 
Table 5 Distribution and statistics summary by age group, sex, and birth tertile

\begin{tabular}{|c|c|c|c|c|c|c|c|c|c|c|c|}
\hline \multirow[t]{2}{*}{ Age } & \multirow[t]{2}{*}{ Sex } & \multicolumn{2}{|c|}{ Chi-squared statistics } & \multicolumn{4}{|c|}{ Absolute distribution $(N)$} & \multicolumn{3}{|c|}{ Relative distribution (\%) $(95 \% \mathrm{Cl})$} & \multirow[b]{2}{*}{$v$} \\
\hline & & $\overline{x^{2}}$ & $P$ value & Total & T1 & T2 & T3 & $\mathrm{T1}$ & T2 & T3 & \\
\hline \multirow[t]{3}{*}{$\leq 6$} & Both & 129.8 & $<0.001$ & 3528 & 1435 & 1281 & 812 & $40.7(39.1-42.3)$ & $36.3(34.7-37.9)$ & $23.0(21.7-24.4)$ & 0.31 \\
\hline & Male & 91.3 & $<0.001$ & 1859 & 757 & 704 & 398 & $40.7(38.5-43.0)$ & $37.9(35.7-40.1)$ & $21.4(19.6-23.3)$ & 0.33 \\
\hline & Female & 45.9 & $<0.001$ & 1668 & 678 & 577 & 413 & $40.6(38.3-43.0)$ & $34.6(32.3-36.9)$ & $24.8(22.7-26.9)$ & 0.29 \\
\hline \multirow[t]{3}{*}{$7-8$} & Both & 90.2 & $<0.001$ & 7336 & 2822 & 2509 & 2005 & $38.5(37.4-39.6)$ & $34.2(33.1-35.3)$ & $27.3(26.3-28.4)$ & 0.24 \\
\hline & Male & 46.8 & $<0.001$ & 3788 & 1464 & 1270 & 1054 & $38.6(37.1-40.2)$ & $33.5(32.0-35.0)$ & $27.8(26.4-29.3)$ & 0.24 \\
\hline & Female & 44.4 & $<0.001$ & 3544 & 1355 & 1238 & 951 & $38.2(36.6-39.8)$ & $34.9(33.4-36.5)$ & $26.8(25.4-28.3)$ & 0.24 \\
\hline \multirow[t]{3}{*}{$9-10$} & Both & 29.8 & $<0.001$ & 11125 & 3967 & 3955 & 3203 & $35.7(34.8-36.6)$ & $35.6(34.7-36.4)$ & $28.9(28.0-29.6)$ & 0.16 \\
\hline & Male & 14.5 & $<0.001$ & 5695 & 2036 & 2010 & 1649 & $35.8(34.5-37.0)$ & $35.3(34.1-36.5)$ & $29.0(27.8-30.1)$ & 0.16 \\
\hline & Female & 15.9 & $<0.001$ & 5425 & 1931 & 1942 & 1552 & $35.6(34.3-36.8)$ & $35.8(34.5-37.1)$ & $28.6(27.4-29.8)$ & 0.17 \\
\hline \multirow[t]{3}{*}{$11-15$} & Both & 232.1 & $<0.001$ & 39068 & 14447 & 13755 & 10866 & $37.0(36.5-37.5)$ & $35.2(34.7-35.7)$ & $27.8(27.4-28.3)$ & 0.20 \\
\hline & Male & 119.9 & $<0.001$ & 20998 & 7739 & 7416 & 5843 & $36.9(36.2-37.5)$ & $35.3(34.7-36.0)$ & $27.8(27.2-28.5)$ & 0.19 \\
\hline & Female & 113.3 & $<0.001$ & 18064 & 6708 & 6336 & 5020 & $37.1(36.4-37.8)$ & $35.1(34.4-35.8)$ & $27.8(27.1-28.5)$ & 0.20 \\
\hline \multirow[t]{3}{*}{$16-20$} & Both & 18.2 & $<0.001$ & 41316 & 14873 & 14574 & 11869 & $36.0(35.5-36.5)$ & $35.3(34.8-35.7)$ & $28.7(28.3-29.2)$ & 0.10 \\
\hline & Male & 40.6 & $<0.001$ & 30363 & 10793 & 10749 & 8821 & $35.5(35.0-36.1)$ & $35.4(34.9-35.9)$ & $29.1(28.5-29.6)$ & 0.14 \\
\hline & Female & 49.9 & $<0.001$ & 10944 & 4077 & 3819 & 3048 & $37.3(36.5-38.2)$ & $34.9(34.0-35.8)$ & $27.8(27.0-28.7)$ & 0.18 \\
\hline \multirow[t]{3}{*}{$21-39$} & Both & 19.0 & $<0.001$ & 66230 & 24345 & 22441 & 19444 & $36.8(36.4-37.1)$ & $33.9(33.5-34.2)$ & $29.3(29.0-29.7)$ & 0.09 \\
\hline & Male & 0.8 & 0.686 & 49220 & 17715 & 16746 & 14759 & $36.0(35.6-36.4)$ & $34.0(33.6-34.4)$ & $30.0(29.6-30.4)$ & 0.04 \\
\hline & Female & 76.7 & $<0.001$ & 16995 & 6627 & 5691 & 4677 & $39.0(38.3-39.7)$ & $33.5(32.8-34.2)$ & $27.5(26.9-28.2)$ & 0.18 \\
\hline \multirow[t]{3}{*}{$\geq 40$} & Both & 3.5 & 0.174 & 81756 & 29173 & 27383 & 25200 & $35.7(35.4-36.0)$ & $33.5(33.2-33.8)$ & $30.8(30.5-31.1)$ & 0.06 \\
\hline & Male & 1.3 & 0.536 & 55721 & 19813 & 18669 & 17239 & $35.6(35.2-36.0)$ & $33.5(33.1-33.9)$ & $30.9(30.6-31.3)$ & 0.05 \\
\hline & Female & 4.3 & 0.114 & 25987 & 9354 & 8691 & 7942 & $36.0(35.4-36.6)$ & $33.4(32.8-34.0)$ & $30.6(30.0-31.1)$ & 0.08 \\
\hline \multirow[t]{3}{*}{ All } & Both & 205.0 & $<0.001$ & 244558 & 89036 & 83781 & 71741 & $36.4(36.2-36.6)$ & $34.3(34.1-34.4)$ & $29.3(29.2-29.5)$ & 0.10 \\
\hline & Male & 61.1 & $<0.001$ & 164666 & 59269 & 56492 & 48905 & $36.0(35.8-36.2)$ & $34.3(34.1-34.4)$ & $29.7(29.5-29.9)$ & 0.16 \\
\hline & Female & 192.9 & $<0.001$ & 80077 & 29752 & 27521 & 22804 & $37.3(36.9-37.6)$ & $34.1(33.8-34.5)$ & $28.6(28.3-28.9)$ & 0.12 \\
\hline
\end{tabular}

$X^{2}$ chi-squared statistic, $V$ effect size, Cramer's $V$

Parent population (national birth statistics) was set at expected distribution in chi-squared test

\section{The Relative Age Effect in Youth Athletes}

$\square$ Orienteering $\square$ XC-Ski $1 \square$ XC-Ski $2 \square$ Chess $\square$ E-Sports

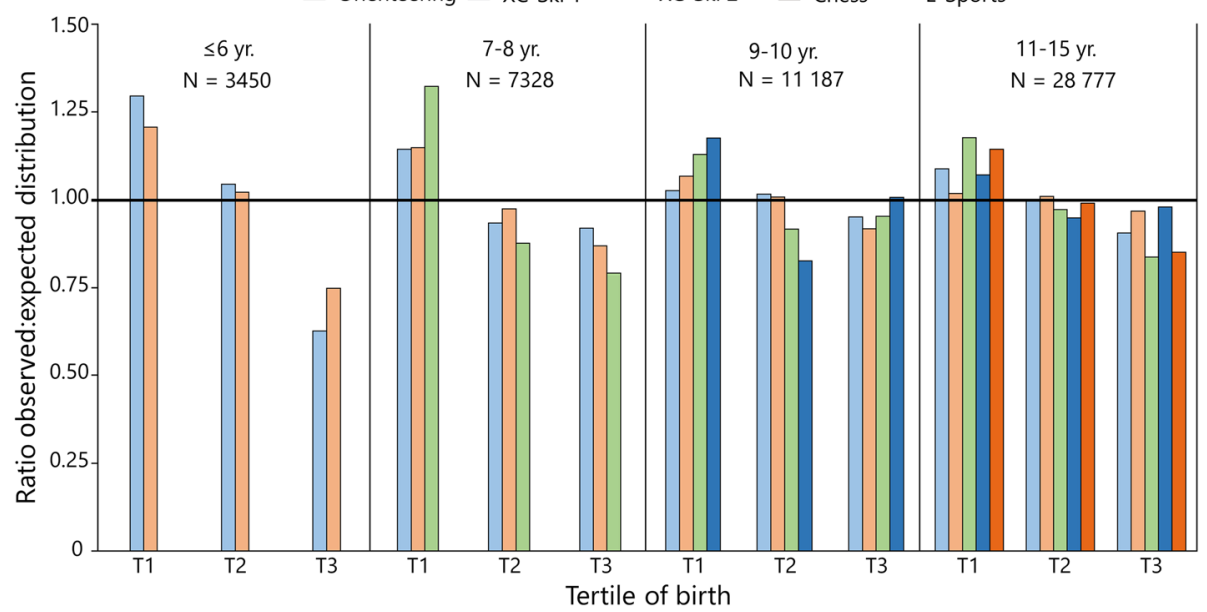

Fig. 1 The relative age effect expressed as the ratio between observed and expected distributions (national birth statistics) of athletes per tertile (T). XC-Ski 1 refers to dataset cross-country skiing ${ }^{1}$ and XC-Ski 2 refers to dataset cross-country skiing ${ }^{2}$. For additional data, see Supplementary file 2 


\section{The Relative Age Effect: Cross-country skiing}

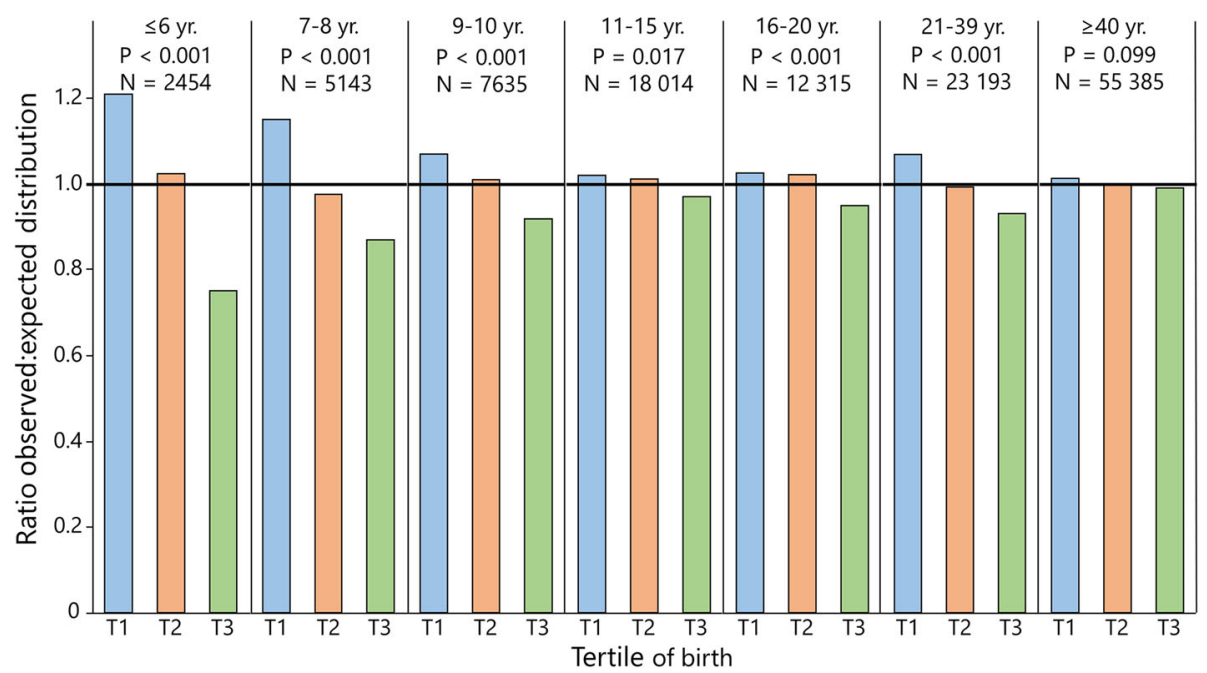

Fig. 2 The relative age effect in Swedish cross-country skiers expressed as the ratio between observed and expected distributions (national birth statistics) of athletes per tertile (T). Data refers to cross-country skiing ${ }^{1}$. For additional data, see Supplementary file 2

parental distribution for corresponding years is not evenly distributed (Supplements 1, 2, and 3).

In E-sports (Fig. 6), RAEs were seen in boys up to 15 years of age $(V=0.25)$. In 21-39-year-old males, an inversed RAE was evident $(V=0.17)$, where age groups $\leq 15,16-20$, and 21-39 years include males only because females constitute of $\sim 3 \%$ of the total population in those age groups. When the whole Esports sample is studied, RAEs are evident for males $(P=0.034, V=0.09)$ but not for females $(P=0.373$, $V=0.14$ ) (Table 5). The RAE in male E-sports players was inversed, while this is only significant for 21 -39-year-olds (ratio T3 $=1.08$ ) when analyzed by age group.

In chess (Fig. 7), RAEs were significant in children up to 10 years of age $(V=0.26)$ but no other subsample when analyzed by age group. As seen in Table 5 , a pooled analysis on all chess players shows significant RAEs, when analyzed by sex only in males. The significant RAE is atypical, with $\mathrm{T} 2$ consistently being underrepresented, while $\mathrm{T} 1$ and $\mathrm{T} 3$ being overrepresented (Supplements 2 and 3).

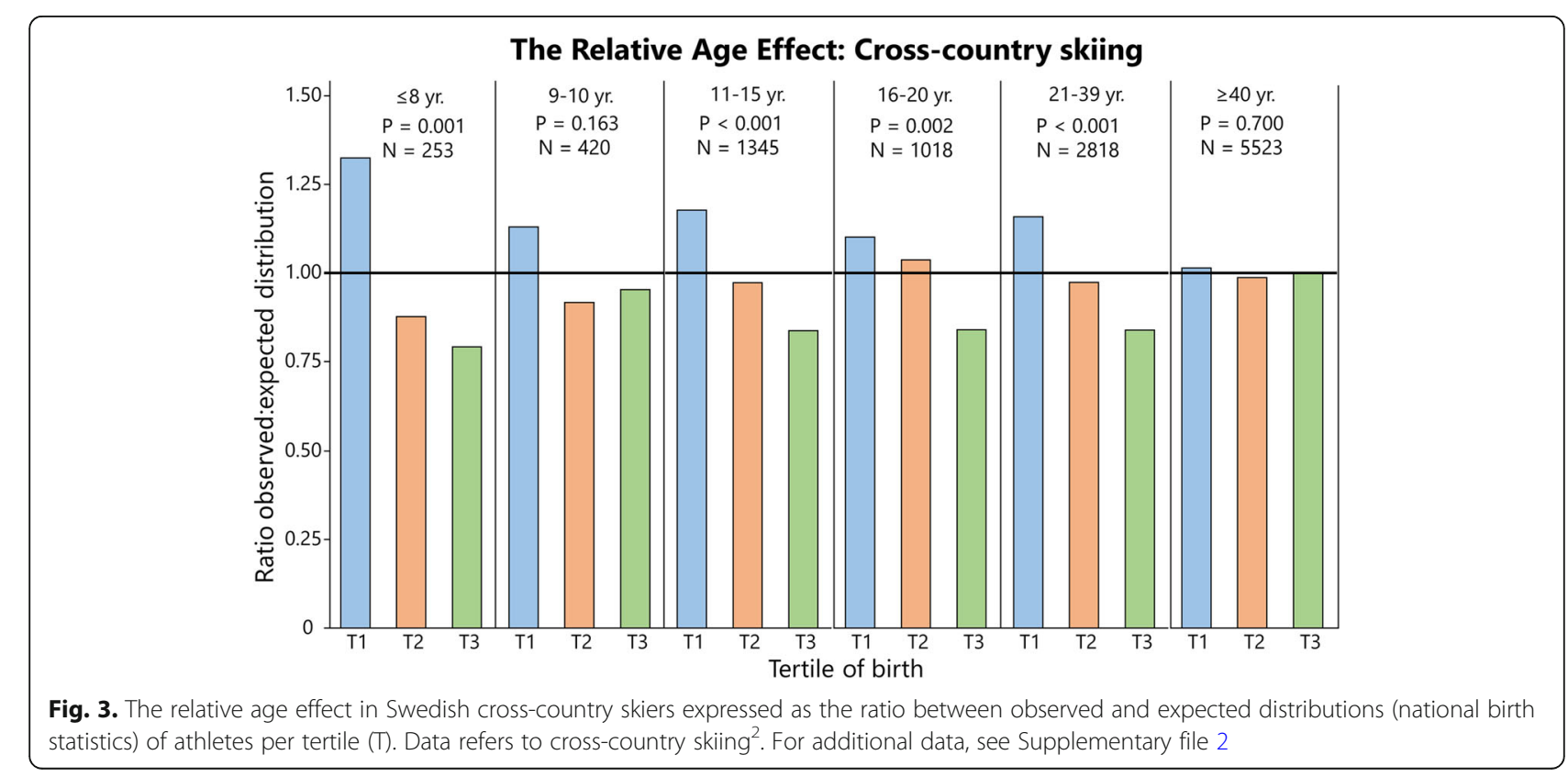




\section{The Relative Age Effect in Sports}

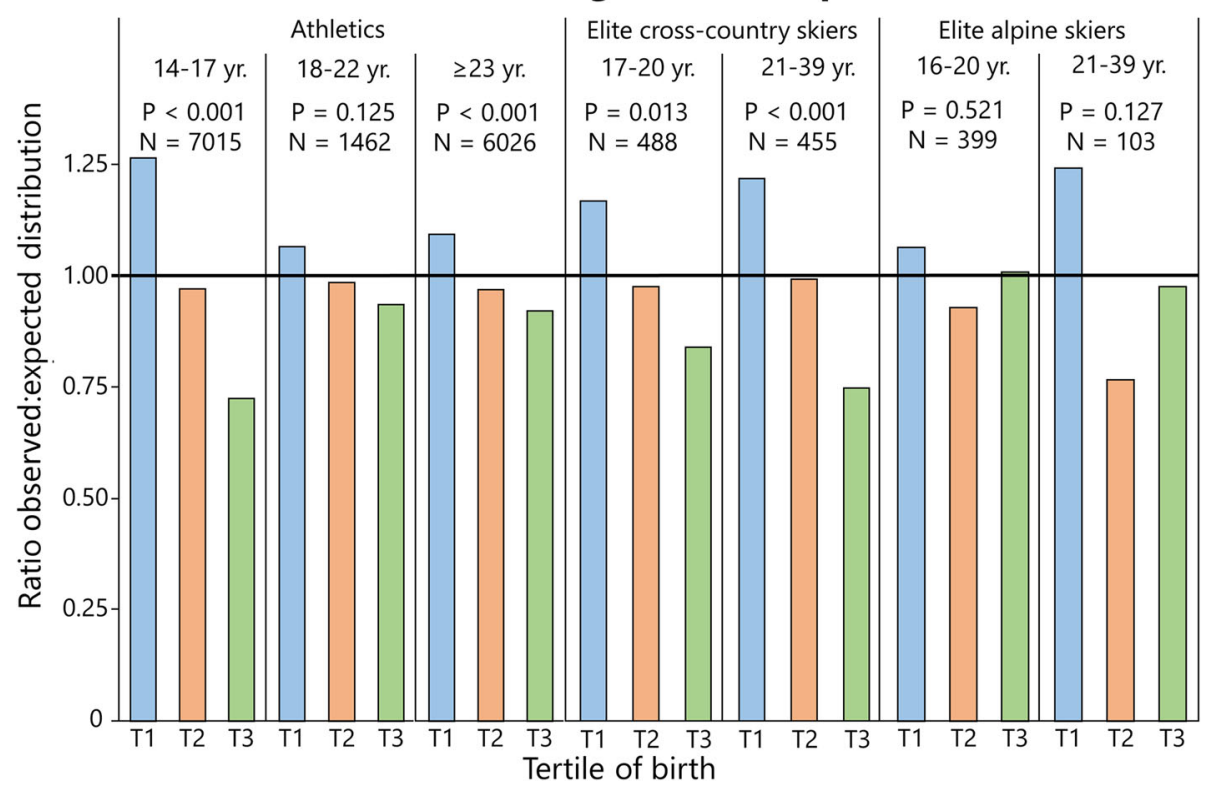

Fig. 4 The relative age effect in Swedish athletic athletes, elite cross-country skiers (dataset cross-country skiing ${ }^{3}$ and elite alpine skiers) expressed as the ratio between observed and expected distributions (national birth statistics) of athletes per tertile (T). For additional data, see Supplementary file 2

\section{Rating and Performance by Birth Tertile}

Rating (cross-country skiing and chess) and ranking (orienteering) data are summarized in Tables 6 and 7, respectively, and depicted in Figs. 8, 9 and 10. Performance data for $100 \mathrm{~m}$ and javelin are summarized in Tables 8 and 9, respectively, and depicted in Figs. 11 and 12. Data on $1500 \mathrm{~m}$ is found in Supplement 4.
In cross-country skiing ${ }^{2}$, earlier born boys aged 11-15 years were higher rated than later-born peers, while there was no difference in other age groups. When pooling all age groups, T1 had a significantly higher rating than T3 in males $(P=0.026$, Supplement 4$)$. In orienteers, there was no difference in ranking between tertiles in any age group. In chess, the only differences were found in female young adolescents and female

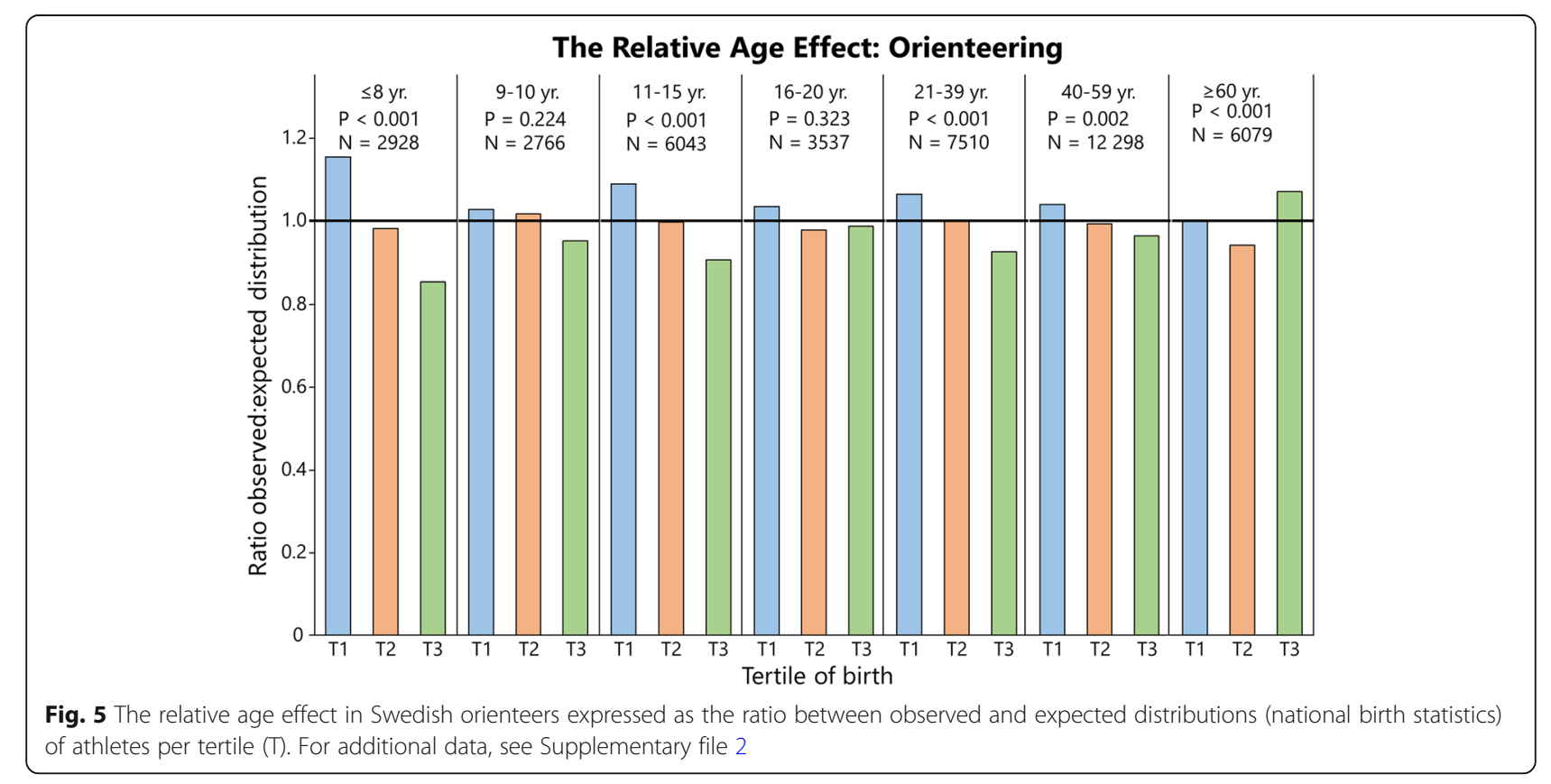




\section{The Relative Age Effect: E-Sports}

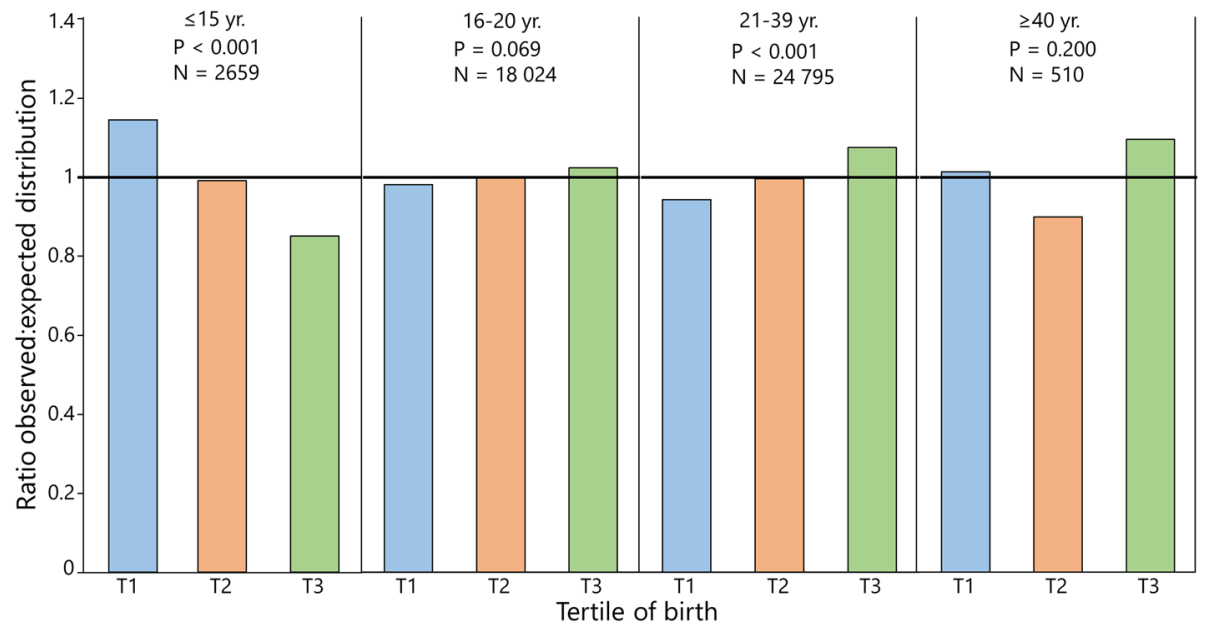

Fig. 6 The relative age effect in Swedish E-sports players expressed as the ratio between observed and expected distributions (national birth statistics) of athletes per tertile (T). Age groups $\leq 15,16-20$, and 21-39years include males only. For additional data, see Supplementary file 2

adolescent, where T1 was better ranked than T2. For athletics, there was no difference in performance for adults in $100 \mathrm{~m}, 1500 \mathrm{~m}$ (Supplement 3), or javelin. In $100 \mathrm{~m}$, athletes born in T3 performed better than earlier born peers for 16- and 22-year-old males. In javelin performance, there was no difference between tertiles in males, while $\mathrm{T} 3$ athletes were inferior to $\mathrm{T} 1$ and $\mathrm{T} 3$ athletes in some female age groups (Table 9).

\section{Discussion}

The present study is one of the most comprehensive on the relative age effect in sports, also investigating birthdates in relation to sports performance. The objective was to determine the magnitude and prevalence of RAEs in different individual sports, by age groups and sex, and in relation to physical performance. Our results show that RAEs are consistently prevalent in most individual sports in Sweden, both physically demanding and cognitive/skill-based. In general, no correlation between birthdate and performance was observed, neither in elite nor in recreational athletes. Findings of skewed birthdate distribution in all athletic populations should be viewed from both sports and health perspectives, and in light of the United Nations' CRC.

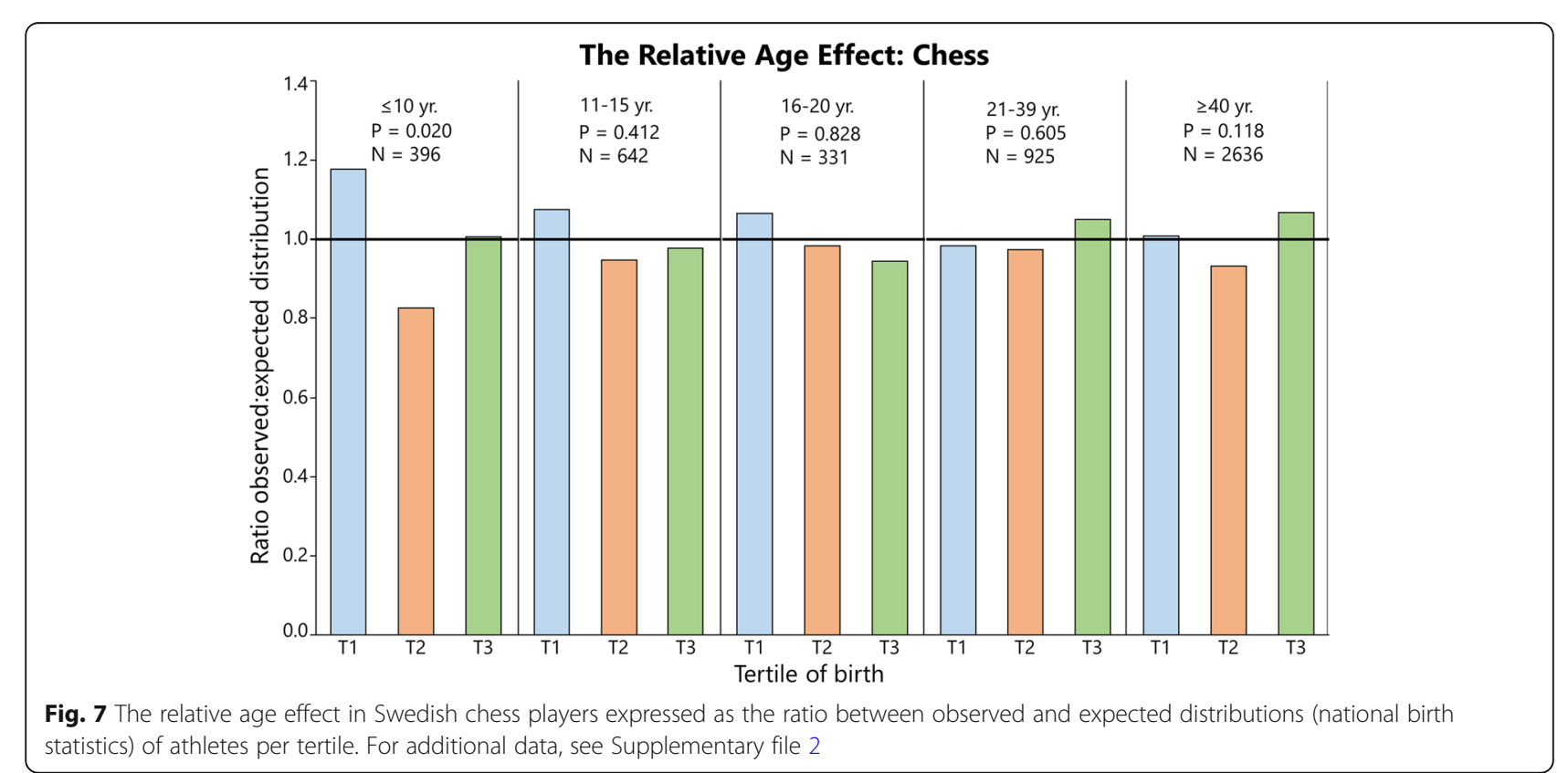


Table 6 Rating by age group, sex, and birth tertile in cross-country skiing and chess

\begin{tabular}{|c|c|c|c|c|c|c|c|c|c|}
\hline \multirow[t]{2}{*}{ Sport } & \multirow[t]{2}{*}{ Age } & \multirow[t]{2}{*}{ Sex } & \multicolumn{2}{|c|}{ Kruskal-Wallis } & \multicolumn{2}{|c|}{ Steel-Dwass } & \multicolumn{3}{|c|}{ Rating (median \pm IQR) } \\
\hline & & & $\overline{x^{2}}$ & $P$ value & Levels & $P$ value & $\overline{\mathrm{T} 1}$ & T2 & T3 \\
\hline \multirow[t]{11}{*}{ Cross-country skiing $^{2}$} & $\leq 10$ & Boys & 6.1 & 0.048 & T1-T3 & 0.052 & $400 \pm 79.3$ & $375 \pm 84.0$ & $378 \pm 78.0$ \\
\hline & & Girls & 1.9 & 0.391 & - & - & $376 \pm 52.5$ & $361 \pm 74.0$ & $362 \pm 87.3$ \\
\hline & $11-15$ & Boys & 15.7 & $<0.001$ & $\mathrm{~T} 1-\mathrm{T} 2$ & 0.018 & $499 \pm 122.0$ & $477 \pm 109.0$ & $469 \pm 117.3$ \\
\hline & & & & & $\mathrm{T} 1-\mathrm{T} 3$ & $<0.001$ & & & \\
\hline & & Girls & 3.4 & 0.185 & - & - & $448 \pm 128.5$ & $445 \pm 106.5$ & $429 \pm 125.8$ \\
\hline & $16-20$ & Men & 0.0 & 0.965 & - & - & $722 \pm 162.5$ & $737 \pm 166.0$ & $722 \pm 210.0$ \\
\hline & & Women & 0.1 & 0.995 & - & - & $615 \pm 197.0$ & $601 \pm 180.0$ & $607 \pm 185.0$ \\
\hline & $21-39$ & Men & 0.9 & 0.644 & - & - & $677 \pm 230.0$ & $686 \pm 212.3$ & $673 \pm 219.5$ \\
\hline & & Women & 0.9 & 0.652 & - & - & $592 \pm 229.0$ & $629 \pm 260.5$ & $586 \pm 253.8$ \\
\hline & $\geq 40$ & Men & 1.7 & 0.425 & - & - & $548 \pm 152.5$ & $527 \pm 145.0$ & $534 \pm 136.5$ \\
\hline & & Women & 0.5 & 0.796 & - & - & $474 \pm 83.8$ & $446 \pm 171.0$ & $475 \pm 125.0$ \\
\hline \multirow[t]{10}{*}{ Chess } & $\leq 10$ & Boys & 5.1 & 0.078 & - & - & $910 \pm 220.0$ & $896 \pm 192.0$ & $860 \pm 200.0$ \\
\hline & & Girls & 0.2 & 0.929 & - & - & $896 \pm 312.0$ & $900 \pm 219.3$ & $850 \pm 208.0$ \\
\hline & $11-15$ & Boys & 0.3 & 0.872 & - & - & $1100 \pm 217.0$ & $1100 \pm 223.8$ & $1080 \pm 223.0$ \\
\hline & & Girls & 7.8 & 0.020 & $\mathrm{~T} 1-\mathrm{T} 2$ & 0.018 & $1102 \pm 276.0$ & $1020 \pm 159.3$ & $1072 \pm 169.0$ \\
\hline & $16-20$ & Men & 2.9 & 0.233 & - & - & $1392 \pm 495.3$ & $1335 \pm 416.3$ & $1322 \pm 405.0$ \\
\hline & & Women & 9.1 & 0.011 & $\mathrm{~T} 1-\mathrm{T} 2$ & 0.019 & $1498 \pm 383.8$ & $1121 \pm 252.8$ & $1290 \pm 311.3$ \\
\hline & $21-39$ & Men & 4.0 & 0.138 & - & - & $1760 \pm 542.8$ & $1683 \pm 590.0$ & $1802 \pm 540.0$ \\
\hline & & Women & 2.0 & 0.375 & - & - & $1565 \pm 751.8$ & $1738 \pm 391.5$ & $1599 \pm 267.5$ \\
\hline & $\geq 40$ & Men & 0.0 & 0.991 & - & - & $1712 \pm 408.0$ & $1725 \pm 443.0$ & $1705 \pm 442.0$ \\
\hline & & Women & 0.5 & 0.797 & - & - & $1344 \pm 972.0$ & $1408 \pm 750.5$ & $1245 \pm 548.0$ \\
\hline
\end{tabular}

$X^{2}$ chi-squared statistic, IQR interquartile range, $T$ tertile

Levels "T1-T3" means that T1 was better performing then $\mathrm{T} 3$

\section{Subgroup Analyses}

When stratified by age group, greater magnitude (distribution skewness, expected/observed ratio, and effect sizes) of RAEs was seen in the youngest $(\leq 6$ years; $V=0.31$ ) and lower in older ( $\geq 40$ years; $V=$ $0.06)$ age categories. These findings are in line with previous research $[35,43]$, proposing a decline in the influence of maturation and growth with increased age, and must be a result either of participants born early in the season leaving sports at a later age, or a re-entry of participants with later birthdates.

In older adults ( $\geq 60$ years), and even stronger in $\geq$ 65 years, an inversed RAE was found in male crosscountry skiing ${ }^{2}$ and orienteers of both sexes. This can potentially be an effect of late-born individuals returning to sports later in life, after not having an equal chance against their early-born peers during

Table 7 Ranking age group, sex and birth tertile in Swedish orienteering

\begin{tabular}{|c|c|c|c|c|c|c|}
\hline \multirow[t]{2}{*}{ Age } & \multirow[t]{2}{*}{ Sex } & \multicolumn{2}{|c|}{ Kruskal-Wallis } & \multicolumn{3}{|c|}{ Ranking median \pm IQR } \\
\hline & & $\overline{x^{2}}$ & $P$ value & $\overline{\mathrm{T} 1}$ & T2 & T3 \\
\hline \multirow[t]{2}{*}{$11-15$} & Men & 0.40 & 0.817 & $4117 \pm 4206.8$ & $4220 \pm 3584.8$ & $3865 \pm 3031.5$ \\
\hline & Women & 0.33 & 0.847 & $2072 \pm 2553.0$ & $2160 \pm 1865.0$ & $2141 \pm 1400.3$ \\
\hline \multirow[t]{2}{*}{$16-20$} & Men & 0.97 & 0.615 & $2279 \pm 4658.0$ & $2918 \pm 4279.0$ & $3113 \pm 4140.0$ \\
\hline & Women & 0.15 & 0.928 & $1718 \pm 2303.0$ & $1741 \pm 2266.5$ & $1691 \pm 2445.8$ \\
\hline \multirow[t]{2}{*}{$21-39$} & Men & 0.36 & 0.834 & $4827 \pm 4935.8$ & $4778 \pm 5009.8$ & $4689 \pm 5179.0$ \\
\hline & Women & 0.45 & 0.800 & $2740 \pm 2722.0$ & $2777 \pm 2585.0$ & $2760 \pm 2399.0$ \\
\hline \multirow[t]{2}{*}{$\geq 40$} & Men & 0.93 & 0.636 & $4038 \pm 3873.8$ & $4010 \pm 3693.0$ & $4078 \pm 3761.8$ \\
\hline & Women & 0.87 & 0.649 & $2322 \pm 2062.0$ & $2257 \pm 2041.0$ & $2233 \pm 2241.0$ \\
\hline
\end{tabular}




\section{Rating by birth date: Cross-country skiing}

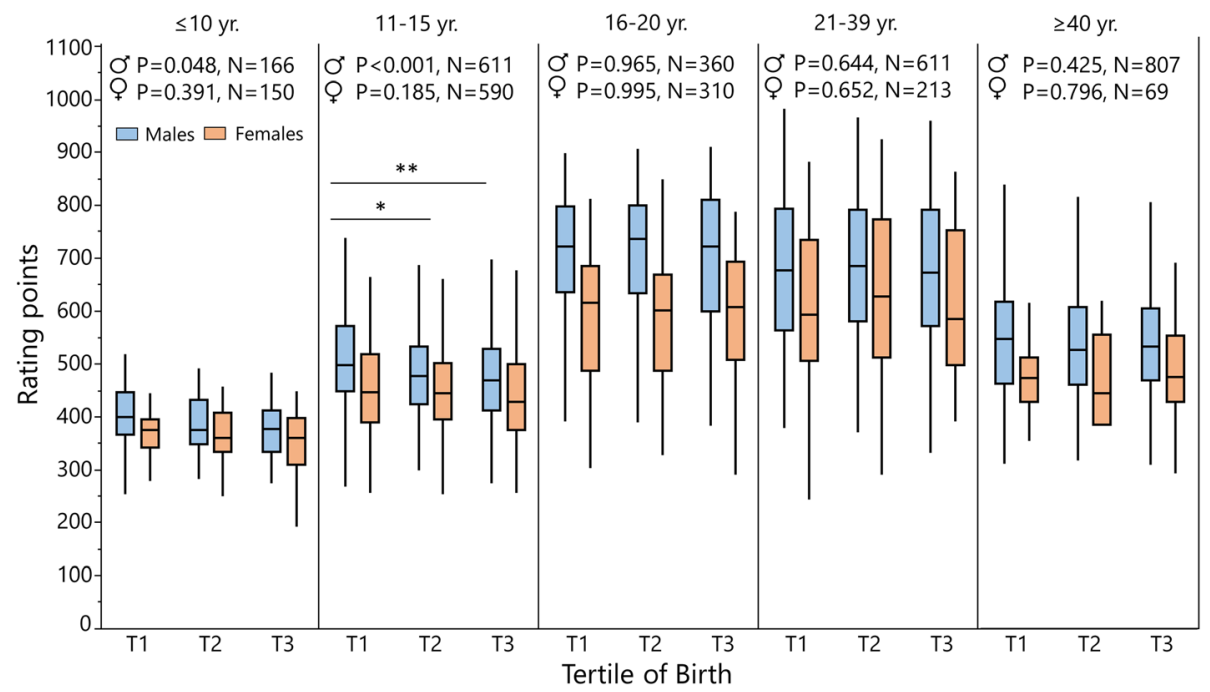

Fig. 8 Rating points (i.e., higher is better) for Swedish cross-country skiers analyzed by birth tertile (T) and sex in different age groups with Kruskal-Wallis one-way analysis of variance (statistics at the top of the figure), when significant followed by Steel-Dwass post-hoc test for multiple comparison between groups. The boundary of the box closest to zero indicates the 25 th percentile, the line within the box marks the median, and the boundary of the box farthest from zero indicates the 75th percentile. End of whiskers represents the lowest and highest data point within $1.5 \times$ interquartile range of the first and third quartile. ${ }^{*} P \leq 0.05,{ }^{*} P \leq 0.01$

childhood and adolescents. In the youngest age groups $(<10$ years), multiple environmental constraints may influence children's participation in sports [48], including parents' reluctance to enroll later-born/maturing children $[16,49]$, more so with higher socioeconomic status [50]. It can be a fair assumption that among the youngest, other factors than the children's will causes the pronounced RAE [16, 48-50]. At this young age, parents most likely decide when, where, and how the child participates in activities. In adolescence, selection is more often done by coaches.

When pooling sport types (Table 3), RAEs are significant in both physical sports and skill-based sports $(V=$ 0.23 and 0.09 , respectively) but with an important difference: The RAE in skill-based sports is inversed, with a slight overrepresentation in T3 (ratio $=1.02$, supplementary

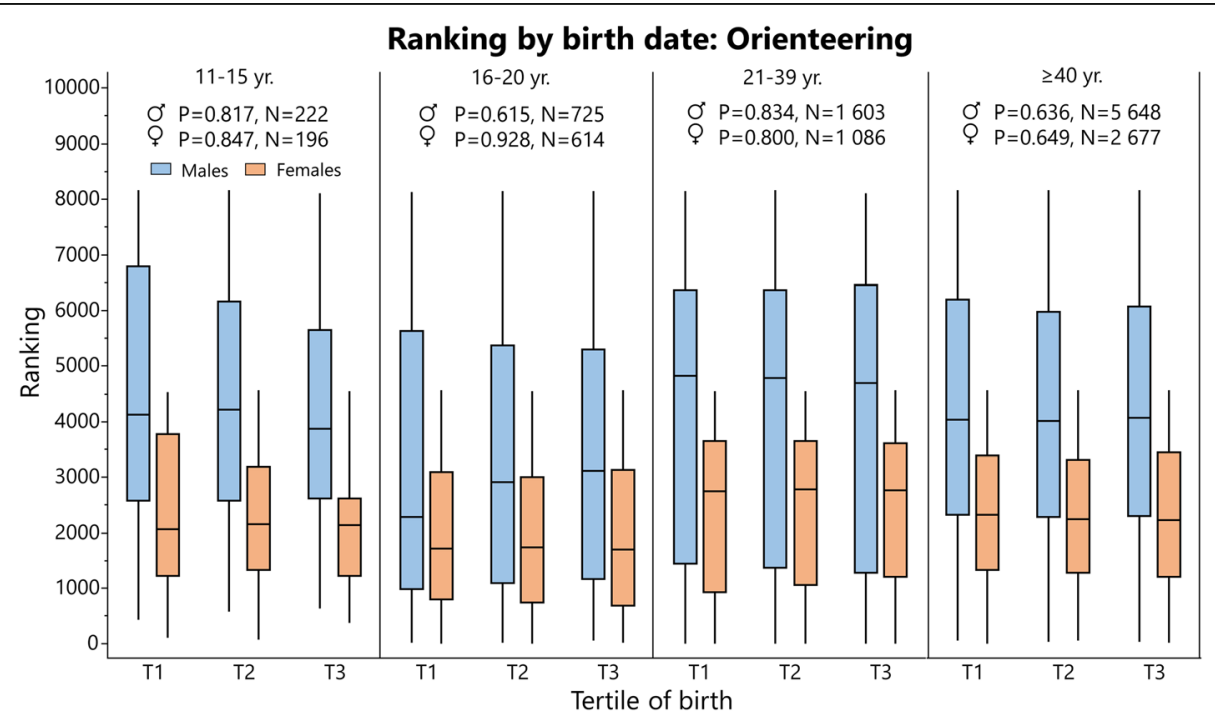

Fig. 9 Ranking (i.e., lower is better) for Swedish orienteers analyzed by birth tertile (T) and sex in different age groups with Kruskal-Wallis one-way analysis of variance (statistics at the top of the figure). The boundary of the box closest to zero indicates the 25th percentile, the line within the box marks the median, and the boundary of the box farthest from zero indicates the 75th percentile. End of whiskers represents the lowest and highest data point within $1.5 \times$ interquartile range of the first and third quartile 


\section{Rating by birth date: Chess}

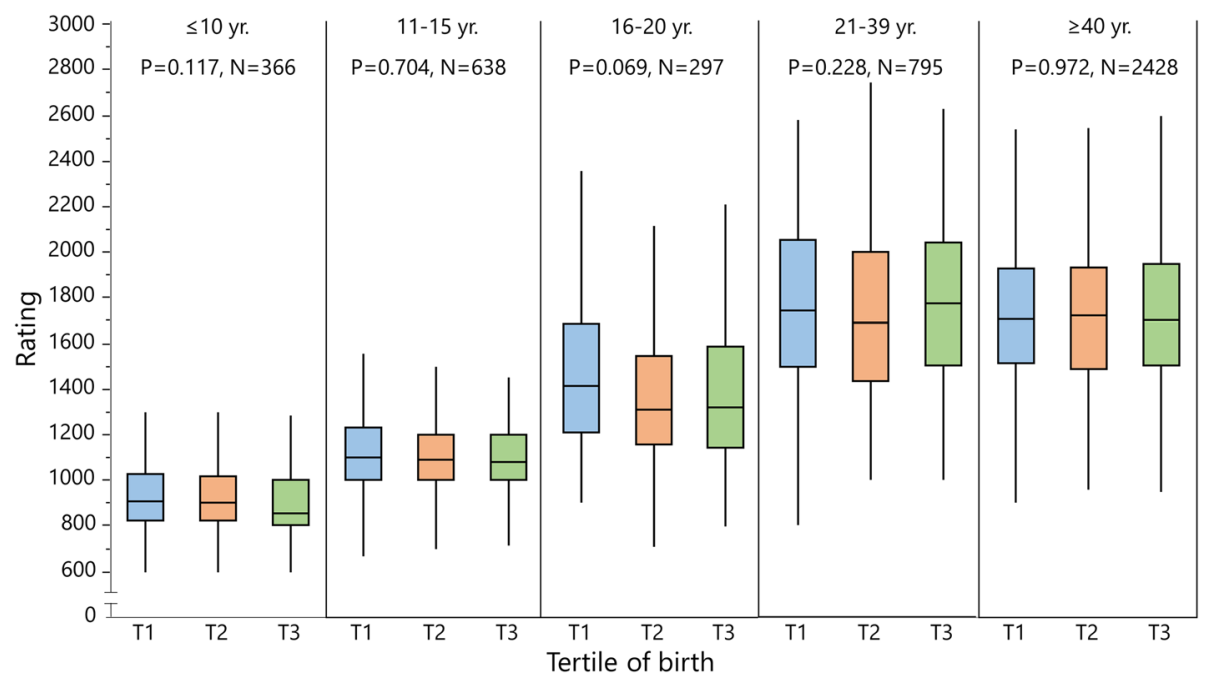

Fig. 10 Rating (i.e., higher is better) for Swedish chess players analyzed by birth tertile ( $T$ ) in different age groups with Kruskal-Wallis one-way analysis of variance (statistics at the top of the figure). For this figure, both sexes are pooled (similar rating points between sexes). The boundary of the box closest to zero indicates the 25th percentile, the line within the box marks the median, and the boundary of the box farthest from zero indicates the 75 th percentile. End of whiskers represents the lowest and highest data point within $1.5 \times$ interquartile range of the first and third quartile

material 4). This is mostly explained by male adults (21-39 years), which is by far the largest cohort in the skill-based sport types, and the only subgroup with an inversed RAE. Even distributions or inversed RAEs have been found in other non-physical skill-based sports, such as shooting $[42,51]$. While not investigated in this study, sports with a high degree of technical skills and esthetics (such as gymnastics, dance, and figure skating) have been found to have no, inversed, or atypical RAEs $[39,52]$ discussed in detail by others $[39,48,52,53]$.

Table 8 Performance in $100 \mathrm{~m}$ by age group, sex, and birth tertile Swedish athletics

\begin{tabular}{|c|c|c|c|c|c|c|c|c|c|}
\hline \multirow[t]{2}{*}{ Age } & \multirow[t]{2}{*}{ Sex } & \multicolumn{3}{|c|}{ ANOVA } & \multicolumn{2}{|c|}{ Tukey's } & \multicolumn{3}{|c|}{ Result(s) mean \pm SD } \\
\hline & & $N$ & $\mathrm{~F}$ ratio & $P$ & Levels & $P$ & $\mathrm{~T} 1$ & $\mathrm{~T} 2$ & T3 \\
\hline \multirow[t]{2}{*}{14} & Male & 263 & 0.30 & 0.740 & & & $11.98 \pm 0.47$ & $12.03 \pm 0.34$ & $12.05 \pm 0.46$ \\
\hline & Female & 560 & 0.55 & 0.580 & & & $12.74 \pm 0.36$ & $12.77 \pm 0.32$ & $12.76 \pm 0.36$ \\
\hline \multirow[t]{2}{*}{15} & Male & 464 & 0.38 & 0.684 & & & $11.55 \pm 0.35$ & $11.57 \pm 0.37$ & $11.53 \pm 0.43$ \\
\hline & Female & 726 & 0.49 & 0.614 & & & $12.78 \pm 0.32$ & $12.8 \pm 0.3$ & $12.77 \pm 0.33$ \\
\hline \multirow[t]{3}{*}{16} & Male & 914 & 5.41 & 0.005 & $\mathrm{~T} 3-\mathrm{T} 1$ & 0.019 & $11.49 \pm 0.28$ & $11.55 \pm 0.26$ & $11.48 \pm 0.29$ \\
\hline & & & & & $\mathrm{T} 3-\mathrm{T} 2$ & 0.011 & & & \\
\hline & Female & 816 & 1.78 & 0.169 & & & $12.72 \pm 0.29$ & $12.75 \pm 0.28$ & $12.76 \pm 0.31$ \\
\hline \multirow[t]{2}{*}{17} & Male & 993 & 3.18 & 0.042 & $\mathrm{~T} 2-\mathrm{T} 3$ & 0.047 & $11.51 \pm 0.26$ & $11.47 \pm 0.31$ & $11.53 \pm 0.27$ \\
\hline & Female & 670 & 1.14 & 0.319 & & & $12.70 \pm 0.30$ & $12.74 \pm 0.28$ & $12.74 \pm 0.29$ \\
\hline \multirow[t]{2}{*}{19} & Male & 1116 & 1.76 & 0.173 & & & $11.46 \pm 0.28$ & $11.44 \pm 0.3$ & $11.42 \pm 0.31$ \\
\hline & Female & 565 & 1.06 & 0.346 & & & $12.64 \pm 0.32$ & $12.64 \pm 0.29$ & $12.59 \pm 0.32$ \\
\hline \multirow[t]{3}{*}{22} & Male & 610 & 7.43 & $<0.001$ & $\mathrm{~T} 3-\mathrm{T} 1$ & 0.003 & $11.36 \pm 0.30$ & $11.26 \pm 0.36$ & $11.25 \pm 0.33$ \\
\hline & & & & & $\mathrm{T} 2-\mathrm{T} 1$ & 0.005 & & & \\
\hline & Female & 343 & 2.95 & 0.054 & & & $12.43 \pm 0.38$ & $12.54 \pm 0.35$ & $12.48 \pm 0.38$ \\
\hline \multirow[t]{2}{*}{$\geq 23$} & Male & 196 & 2.06 & 0.130 & & & $11.35 \pm 0.32$ & $11.36 \pm 0.35$ & $11.24 \pm 0.38$ \\
\hline & Female & 88 & 1.66 & 0.196 & & & $12.50 \pm 0.39$ & $12.57 \pm 0.30$ & $12.40 \pm 0.31$ \\
\hline
\end{tabular}


Table 9 Javelin performance by age group, sex and birth tertile in Swedish athletics

\begin{tabular}{|c|c|c|c|c|c|c|c|c|c|}
\hline \multirow[t]{2}{*}{ Age } & \multirow[t]{2}{*}{ Sex } & \multicolumn{3}{|c|}{ ANOVA } & \multicolumn{2}{|c|}{ Tukey's } & \multicolumn{3}{|c|}{ Result $(\mathrm{cm})$ mean \pm SD } \\
\hline & & $N$ & $\mathrm{~F}$ ratio & $P$ & Levels & $P$ & $\mathrm{~T} 1$ & T2 & T3 \\
\hline \multirow[t]{2}{*}{14} & Male & 279 & 0.73 & 0.485 & & & $4134 \pm 490$ & $4120 \pm 561$ & $4032 \pm 340$ \\
\hline & Female & 683 & 1.00 & 0.368 & & & $3204 \pm 489$ & $3228 \pm 554$ & $3146 \pm 412$ \\
\hline \multirow[t]{2}{*}{15} & Male & 441 & 0.08 & 0.927 & & & $4439 \pm 598$ & $4431 \pm 510$ & $4461 \pm 570$ \\
\hline & Female & 823 & 0.53 & 0.591 & & & $3126 \pm 459$ & $3124 \pm 483$ & $3094 \pm 432$ \\
\hline \multirow[t]{2}{*}{16} & Male & 462 & 1.43 & 0.241 & & & $4656 \pm 734$ & $4716 \pm 653$ & $4561 \pm 580$ \\
\hline & Female & 1070 & 0.35 & 0.702 & & & $3126 \pm 474$ & $3124 \pm 545$ & $3094 \pm 547$ \\
\hline \multirow[t]{3}{*}{17} & Male & 500 & 0.23 & 0.794 & & & $4791 \pm 729$ & $4754 \pm 661$ & $4813 \pm 734$ \\
\hline & Female & 712 & 5.07 & 0.007 & $\mathrm{~T} 1-\mathrm{T} 3$ & 0.0451 & $3203 \pm 531$ & $3250 \pm 564$ & $3084 \pm 512$ \\
\hline & & & & & $\mathrm{T} 2-\mathrm{T} 3$ & 0.0056 & & & \\
\hline \multirow[t]{2}{*}{19} & Male & 610 & 0.82 & 0.443 & & & $5000 \pm 676$ & $5079 \pm 777$ & $5069 \pm 747$ \\
\hline & Female & 688 & 2.90 & 0.056 & & & $3276 \pm 521$ & $3321 \pm 690$ & $3177 \pm 545$ \\
\hline \multirow[t]{3}{*}{22} & Male & 336 & 1.36 & 0.257 & & & $5276 \pm 777$ & $5444 \pm 920$ & $5296 \pm 679$ \\
\hline & Female & 324 & 4.23 & 0.015 & $\mathrm{~T} 1-\mathrm{T} 3$ & 0.0174 & $3478 \pm 666$ & $3476 \pm 700$ & $3206 \pm 624$ \\
\hline & & & & & T2-T3 & 0.0313 & & & \\
\hline \multirow[t]{2}{*}{$\geq 23$} & Male & 295 & 0.82 & 0.440 & & & $5219 \pm 778$ & $5151 \pm 653$ & $5082 \pm 694$ \\
\hline & Female & 174 & 2.59 & 0.078 & & & $3333 \pm 700$ & $3182 \pm 580$ & $3065 \pm 585$ \\
\hline
\end{tabular}

ANOVA analysis of variance, $S D$ standard deviation, $T$ tertile Levels "T1-T3" means that T1 was better performing then T3

One possibility is that relatively younger individual's dropout from physical sports, to focus more on studies or other hobbies, is a parental decision when the child lags behind in performance. Potentially, this could influence the inverse RAE in some E-sports cohorts. Meanwhile, E-sports today is possibly more competitive than $10-20$ years ago, and in youths, being relatively older could be a competitive advantage. Speculatively, this could influence the RAE in youths compared to the inversed RAE in adults.

In the present study, RAEs were most prominent in physical sports such as cross-country skiing (both

\section{Performance by birth date: $100 \mathrm{~m}$}

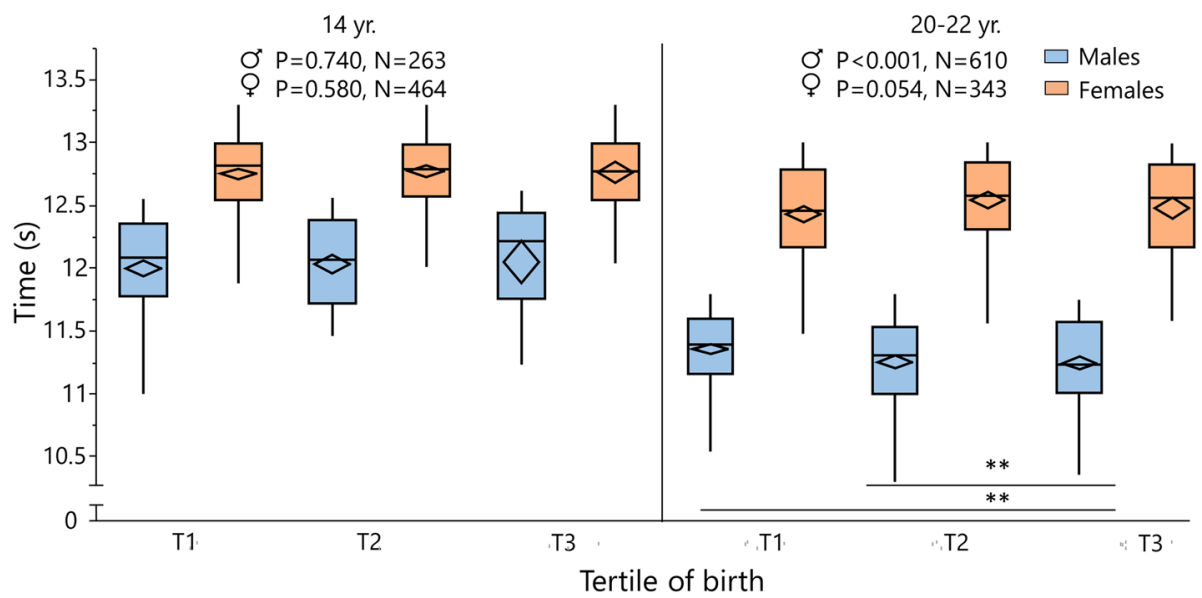

Fig. 11 Performance for Swedish athletes in $100 \mathrm{~m}$, analyzed by birth tertile (T) and sex in different age groups with one-way analysis of variance (statistics at the top of the figure). When significant followed by Tukey's post-hoc test for multiple comparison between groups. The boundary of the box closest to zero indicates the 25th percentile, the line within the box marks the median, the confidence diamond contains the mean and the upper and lower $95 \%$ of the mean, and the boundary of the box farthest from zero indicates the 75th percentile. End of whiskers represents the lowest and highest data point within $1.5 \times$ interquartile range of the first and third quartile. ${ }^{* *} P \leq 0.01$ 


\section{Performance by birth date: Javelin}

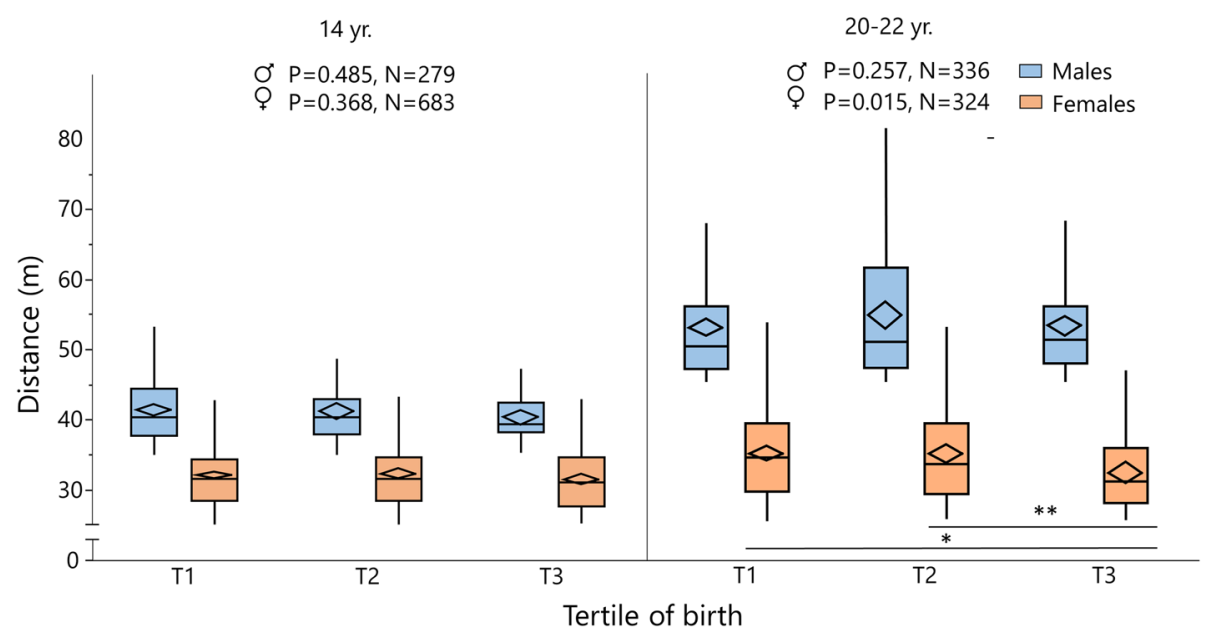

Fig. 12 Performance for Swedish athletes in javelin, analyzed by birth tertile $(T)$ and sex in different age groups with one-way analysis of variance (statistics at the top of the figure). When significant followed by Tukey's post-hoc test for multiple comparison between groups. The boundary of the box closest to zero indicates the 25th percentile, the line within the box marks the median, the confidence diamond contains the mean and the upper and lower $95 \%$ of the mean, and the boundary of the box farthest from zero indicates the 75 th percentile. End of whiskers represents the lowest and highest data point within $1.5 \times$ interquartile range of the first and third quartile. ${ }^{*} P \leq 0.05 .{ }^{*} P \leq 0.01$

recreational and elite) and athletics, where T1 constituted of up to $51 \%$ of the athletes in some sub-samples, with large effect sizes, for instance, cross-country skiing boys $\leq 8$ years $(\mathrm{T} 1=51 \%, V=0.43)$ for 14 -year-old athletes in athletics, boys ( $\mathrm{T} 1=51 \%, V=0.45)$ and girls ( $\mathrm{T} 1=48 \%, V=0.41)$. In orienteering, RAEs were significant, but less skewed compared to cross-country skiing and athletics. In the relatively small sample of elite alpine skiers, a RAE was seen only in adult males, in line with previous research demonstrating RAEs in males only [54] or in both sexes [39] (Supplement 2).

It is generally assumed that the magnitude of the RAE in female sports is smaller due to less intense competition among young girls $[42,55]$. Some have suggested that female sports are less strength-related than male sports, making the maturation-related developmental lead less decisive [56]. In the present study, RAEs were consistently seen in both sexes, and we did not observe a smaller overall RAE magnitude in females compared to males, as reported in some previous studies [20, 35, 51]. It has been suggested that relatively older female athletes may be at a greater risk of dropping out of sports [48], possibly due to early maturation that has been associated with increased negative psychosocial outcomes [57]. Further, some propose that a stereotyped definition of femininity could discourage early maturing females from participating in sports, in order to conform to socially constructed gender roles [58]. However, this is not reflected in our results were RAEs are consistently seen in both sexes.
Because most samples included a mix of recreational, competitive, and elite athletes, no sub-analysis was done on the level of competition. However, alpine skiers and cross-country skiing dataset 3 constituted of elite athletes only. As mentioned, alpine skiers showed no RAE when both sexes are pooled, in either junior or senior athletes. Only in adult males, a significant RAE was seen, with a large effect size but a limited sample size $(N=70$, $V=0.39$ ). In elite cross-country skiers, however, RAEs were prevalent in both junior and senior athletes (Fig. 4) as also seen in previous studies [39].

\section{Performance}

Our results show that earlier born children sometimes perform better and are higher ranked than later-born peers. This trend is not seen in adult athletes where, in general, the average performance is the same, regardless of when you are born. There are just not as many athletes born late in the year. There is no surprise that children born earlier in the season also perform betterthey are up to a year older than those born at the end of the season. In athletics, there is in general no difference between tertiles in performance (Figs. 11 and 12, Supplement 4). In some events and age groups, T3 and/or T2 actually performed better than T1. This is contrary to the general concept of RAE [59]. However, the result can be explained by the sample population. It is inevitable that the average level will be roughly the same for all three subgroups; all have been selected according to the same criteria (to place in the top 30). While the performance is equal, the distribution is nevertheless 
skewed. Hence, it is reasonable to say that the late-born adolescents that make the top 30 cut are early physically developed for their age in addition to being talented, while the early-born adolescents are overrepresented due to RAEs.

In this context, it has been shown that early sport success is not an adequate predictor of top-level performance [60]. Rather, entering competitions later is linked to better performance during adulthood [61]. The "underdog hypothesis" should be addressed in this context. The underdog hypothesis contends that, because they are less (physically) mature, relatively younger players must possess or develop superior technical, tactical, and physiological skills to be competitive [62]. In early adulthood, when differences in physical maturity are attenuated, this could in turn be in favor for the relatively younger athletes [63]. Importantly, for this hypothesis to be realized, later maturing/relatively younger athletes must be retained within the sport system. Todays' early talent selection system, present in too many situations, is counter-productive when the goal is to find the very best future athletes.

\section{General RAE Discussion}

Early talent selection, self-determined dropouts [64], or parents' decision not to enroll relatively younger children in sports [48] all contribute to observed RAEs. With an increasing proportion of physical activity taking place in organized forms, such as in sports clubs [31] and the known relationship between childhood and adult physical activity levels [65], RAEs will impact longterm health. Also, being omitted from sports participation due to any of the above reasons violates the CRC, stipulating that the best interest of every child should always be in focus. Coaches' and parents'selection of future elite athletes, annual age-grouping, systems, and adults' administration of competition results must not be an excuse for the facilitation of sports dropout. Early selection and specialization in sports as young creates a requirement for children's performance but is to a large extent a reflection of maturation, not talent and future performance. For those who do not live up to the requirements, there is a risk, or even guarantee, of being excluded from their team.

Should the RAE here seen in individual and previously in most team sports be disregarded because of the survival of the fittest? Nolan and Howell [66] state that the RAE will continue to exist and raise the question: "why shouldn't it?" Why should it not be a Darwinian selection in sport at the highest level, and what says that the system of elimination must be fair? However, our results clearly demonstrate the lack of predictive power in early selection as athletes born early in the year do not perform better compared to their later-born peers. Most importantly, the current system results in discontinuation of physical activity in late-born children. In addition to the health benefits of sports participation, children who drop out of sports experience more social and emotional problems [67].

It has also been appreciated that not everyone has the physical and mental capacities to make it to the top [68]. A fair organization in competitive sports is important for children to develop individually [7], but also for the very best senior athletes to-become not to be negatively selected at an early age in favor for individuals who do not have the future capacity to succeed as elite athletes. A skewed distribution based heavily on birthdate will eliminate future senior elite athletes while passing along the near

\section{Assuming equal talent distribution}

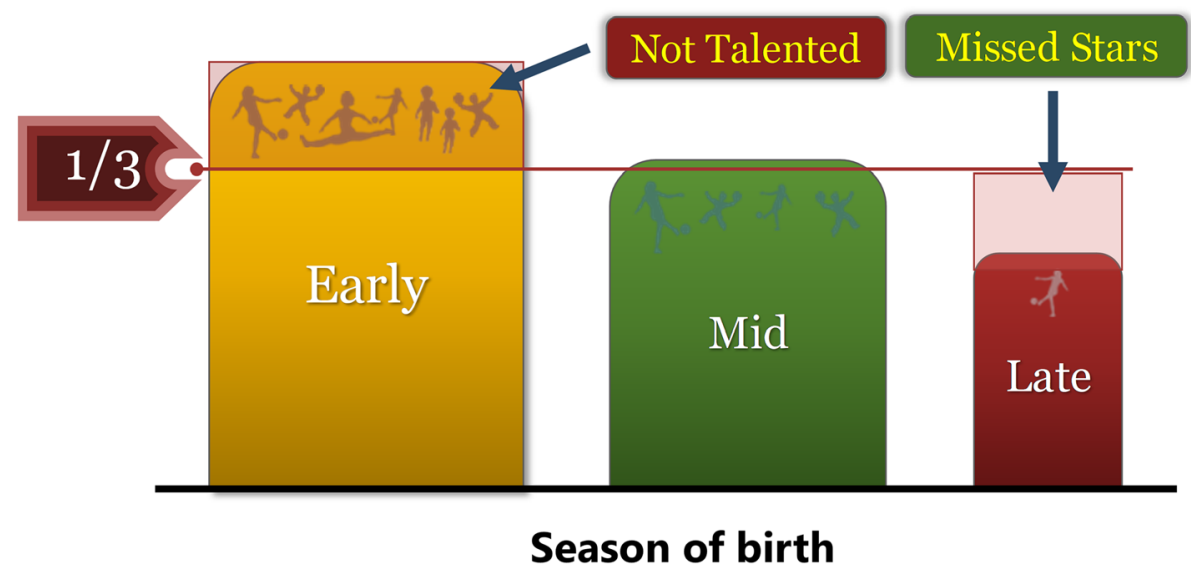

Fig. 13 General distribution of athletes in individual sports in Sweden. Assuming equal talent distribution throughout the year, youth athletes are more likely to continue sports if they are born early. Consequently, some adult elite athletes reach elite level only because they were born early, when not truly talented. At the same time, late-born children, with the potential to become elite athlete, are missed stars due to early dismissal 
elite. This can be viewed as the number of individuals above and below the expected distribution (Fig. 13). Assuming that talented children are born all year around, and not more likely in the spring, some individuals constituting the bars reaching above the expected distribution have made it to an elite level based on skewed selection due to birthdate. Other individuals who should have become elite athletes and contributed to the bars not reaching the expected distribution ever continued their athletic careers due to negative selection in younger years. At no time are all the physiologically and psychologically most suited athletes given the chance to reach their potential. Thus, it can be concluded that "survival of the fittest" in sports is skewed by less-than-optimal selection system and "fittest of the selected" a more appropriate term.

Moesch et al. [69] found that elite athletes pass important steps in their career at a significantly older age than their near-elite peers. Only after the age of 18 years will elite athletes complete more training hours in their sport than near-elite athletes, with a significant difference shown only after the age of 21 years. Also, elite athletes spend significantly fewer years on junior national teams, but more years on senior national teams. This, in combination with the conclusion made by Williams and Reilly [70], where it was seen as extremely difficult to identify those who will eventually reach the top, provides evidence that applying Darwinism on youths will inevitably lead to lower elite performance, as a group, among adult athletes.

To make competitions fair, to ensure that children are treated equally and ultimately develop optimal elite athletes, coaches and parents must be aware of the risk for skewed and inappropriate selections at young age. Loss of talent may be avoided if parents, coaches, and sport federations would allow prediction of success to occur at a later age [7, 27, 71]. Also, Martindale [68] concluded that de-emphasizing agegroup success is a crucial concept to implement in talent development environment and that problems in selection and coaching will continue to exist if not a change in the stress on age group success is eliminated. The current system used in most countries may also disfavor early maturing children in the sense that they live under the impression that success can be reached without effort.

\section{Strengths and Limitations}

A key strength of this study is that the distribution analyses are executed with the true parental distribution as a reference [46]. Also, the large sample size, often lacking in previous examinations, together with the multiple sports included results in a broad and robust examination of the topic. In line with similar research, multiple chi-squared tests have been executed, with no correction for multiple tests. A more stringent approach would reduce type I errors, i.e., false positives. Meanwhile, adjustment for multiple comparisons is not always desirable $[72,73]$. The general result and conclusion would not be different, with a few less rejections of the null hypothesis (equal distribution of athletes).

\section{Conclusions}

The RAE is present in most individual sports in Sweden and seen as early as in children age 3 to 6 years, as well as in older children, adolescents, and adults. A strive for early success eliminates potentially talented young athletes in team sports as well as individual sports. Youth sports should provide opportunities for individual performance development based on growth and maturity during adolescence. Age group squads should not be closed, but open, to provide later maturing athletes with the opportunity to become successful. Young athletes should be selected on skill and ability rather than on physical size. Further, it is necessary to educate leaders and coaches involved in youth sport about the importance, and the possible negative outcomes, of maturation-biased selection and to de-emphasize the importance of age-group success. Failing to address the relative age issue and the causing mechanisms may result in children discontinuing physical activity in general, creating a long-term negative effect on population health.

\section{Supplementary Information}

The online version contains supplementary material available at https://doi. org/10.1186/s40798-021-00300-2.

Additional file 1. The Supplement file 1 can be accessed via the DOl: https://doi.org/10.6084/m9.figshare.12191898.

Additional file 2. The Supplement file 2 can be accessed via the DOI: https://doi.org/10.6084/m9.figshare.12191898.

Additional file 3. The Supplement file 3 can be accessed via the DOI: https://doi.org/10.6084/m9.figshare.12191898.

Additional file 4. The Supplement file 4 can be accessed via the DOI: https://doi.org/10.6084/m9.figshare.12191898.

Additional file 5. The Supplement file 5 can be accessed via the DOl: https://doi.org/10.6084/m9.figshare.12191898.

\section{Abbreviations}

CRC: Convention on the Rights of the Child; RAE: Relative age effect; $\mathrm{T}$ : Tertile; $V$ : Cramer's $V$; $X^{2}$ : Chi-squared statistic

\section{Acknowledgements}

We gratefully acknowledge Johan Nyman, Bo Nordin, and Christer Petterson for their kind provision of data.

\section{Authors' Contributions}

IJ conceptualized the study, wrote the manuscript, analyzed the data, and prepared the figures and datasets. CM conceptualized the study, collected the data, and reviewed and edited the manuscript. GP wrote the scripts and collected, aligned, and cleaned the data from available databases. $\sqcup J$ contributed in the conceptualization, intellectual contribution, and manuscript revision. The authors read and approved the final manuscript. 


\section{Funding}

This study was funded by Umeå School of Sport Sciences Open Access funding provided by Umea University.

\section{Availability of Data and Materials}

All data generated or analyzed during this study are included in this published article and in Figshare data repository. DOI: 10.6084/ m9.figshare.12191898

\section{Ethics Approval and Consent to Participate}

Not applicable

\section{Consent for Publication}

All data is anonymized and collected from open source databases.

\section{Competing Interests}

The authors, Johan Jakobsson, A. Lennart Julin, Glenn Persson, and Christer Malm, declare that they have no competing interests.

\section{Author details}

'Section for Sports Medicine, Department of Community Medicine and Rehabilitation, Umeå University, Gösta Skoglunds väg 3, SE-901 87 Umeå, Sweden. ${ }^{2}$ Swedish Athletic Association, 120 30, Heliosgatan 3, Stockholm, Sweden.

\section{Received: 28 April 2020 Accepted: 12 January 202}

\section{Published online: 01 March 2021}

\section{References}

1. Dudink A. Birth date and sporting success. Nature. 1994;368:592.

2. Kassel C. Birth-months of Genius. Open Court. 1929:63:677-95.

3. Huntington E. Season of birth -its relation to human abilities; 1938.

4. Cobley S, McKenna J, Baker J, Wattie N. How pervasive are relative age effects in secondary school education? J Educ Psychol. 2009;101(2):520.

5. Thompson AH, Barnsley RH, Dyck RJ. A new factor in youth suicide: the relative age effect. Can J Psychiatry. 1999;44(1):82-5.

6. Julin AL. Den okända utstlagningen. Friidrott. 1982:4:12-5.

7. Musch J, Grondin S. Unequal competition as an impediment to personal development: a review of the relative age effect in sport. Dev Rev. 2001; 21(2):147-67.

8. Baxter-Jones A, Helms P. Born too late to win? Nature. 1994;370(6486):186.

9. Stenling A, Holmström S. Evidence of relative age effects in Swedish women's ice hockey. Talent Dev Excell. 2014;6(2):31-40.

10. Addona $V$, Yates PA. A closer look at the relative age effect in the National Hockey League. J Quantitative Anal Sports. 2010;6(4):1-17.

11. Geithner C, MC, Henriksson T, Fjellman-Wiklund A, Gilenstam K. Relative age effects in women's ice hockey. Women Sport Phys Activity J. 2018;26(2): 124-33.

12. Sierra-Diaz MJ, Gonzalez-Villora S, Pastor-Vicedo JC, Serra-Olivares J. Soccer and relative age effect: a walk among elite players and young players. Sports (Basel, Switzerland). 2017;5(1):5

13. Arrieta H, Torres-Unda J, Gil SM, Irazusta J. Relative age effect and performance in the U16, U18 and U20 European Basketball Championships. J Sports Sci. 2016;34(16):1530-4.

14. Helsen, van Winckel J, Williams AM. The relative age effect in youth soccer across Europe. J Sports Sci. 2005;23(6):629-36.

15. Thompson A, Barnsley RH, Stebelsky G. Born to play ball - the relative age effect and major-league baseball. Sociol Sport J. 1991;8(2):146-51.

16. Delorme N, Raspaud M. The relative age effect in young French basketball players: a study on the whole population. Scand J Med Sci Sports. 2009; 19(2):235-42.

17. Jones C, Visek AJ, Barron MJ, Hyman M, Chandran A. Association between relative age effect and organisational practices of American youth football. Sports Sci. 2019:37(10):1146-53. https://doi.org/10.1080/02640414.2018.154 6545.

18. Till K, Cobley S, Wattie N, O'Hara J, Cooke C, Chapman C. The prevalence, influential factors and mechanisms of relative age effects in UK Rugby League. Scand J Med Sci Sports. 2010;20(2):320-9.

19. Cobley S, Hanratty M, O'Connor D, Cotton W. First club location and relative age as influences on being a professional Australian Rugby League player. Int J Sports Sci Coach. 2014;9(2):335-46.
20. Schorer J, Cobley S, Busch D, Brautigam H, Baker J. Influences of competition level, gender, player nationality, career stage and playing position on relative age effects. Scand J Med Sci Sports. 2009;19(5):720-30.

21. Baxter-Jones AD. Growth and development of young athletes. Should competition levels be age related? Sports Med (Auckland, NZ). 1995;20(2): 59-64.

22. Gerdin G, Hedberg M, Hageskog CA. Relative Age Effect in Swedish Male and Female Tennis Players Born in 1998-2001. Sports (Basel, Switzerland). 2018;6(2):38

23. Baxter-Jones AD, Helms P, Maffulli N, Baines-Preece JC, Preece M. Growth and development of male gymnasts, swimmers, soccer and tennis players: a longitudinal study. Ann Hum Biol. 1995;22(5):381-94.

24. Brustio PR, Kearney PE, Lupo C, Ungureanu AN, Mulasso A, Rainoldi A, et al. Relative age influences performance of world-class track and field athletes even in the adulthood. Front Psychol. 2019;10:1395.

25. Cote J, Macdonald DJ, Baker J, Abernethy B. When "where" is more important than "when": birthplace and birthdate effects on the achievement of sporting expertise. J Sports Sci. 2006;24(10):1065-73.

26. Baker J, Logan AJ. Developmental contexts and sporting success: birth date and birthplace effects in national hockey league draftees 2000-2005. Br J Sports Med. 2007:41(8):515-7.

27. Helsen WF, Starkes JL, Van Winckel J. The influence of relative age on success and dropout in male soccer players. Am J Hum Biol. 1998;10(6):791-8.

28. Brustio PR, Lupo C, Ungureanu AN, Frati R, Rainoldi A, Boccia G. The relative age effect is larger in Italian soccer top-level youth categories and smaller in Serie A. PLoS One. 2018:13(4):e0196253.

29. Musch J, Hay R. The relative age effect in soccer: cross-cultural evidence for a systematic discrimination against children born late in the competition year. Sociol Sport J. 1999;16:54-64.

30. Goldschmied N. No evidence for the relative age effect in professional women's sports. Sports Med (Auckland, NZ). 2011;41(1):87-8 author reply 890.

31. Malm C, Jakobsson J, Isaksson A. Physical activity and sports-real health benefits: a review with insight into the public health of Sweden. Sports. 2019;7(5):127.

32. Telama R, Yang X, Viikari J, Välimäki I, Wanne O, Raitakari O. Physical activity from childhood to adulthood: a 21-year tracking study. Am J Prev Med. 2005;28(3):267-73.

33. Assembly UG. Convention on the Rights of the Child. United Nations, Treaty Series. 1989:1577(3):1-23.

34. Riksdag S. UN Convention on the Rights of the Child to become law in Sweden; 2018.

35. Smith KL, Weir PL, Till K, Romann M, Cobley S. Relative age effects across and within female sport contexts: a systematic review and meta-analysis. Sports Med (Auckland, NZ). 2018:48(6):1451-78.

36. Williams $J H$. Relative age effect in youth soccer: analysis of the FIFA U17 World Cup competition. Scand J Med Sci Sports. 2010;20(3):502-8.

37. Hancock DJ, Adler AL, Côté J. A proposed theoretical model to explain relative age effects in sport. Eur J Sport Sci. 2013:13(6):630-7.

38. Anderson G, Ward R. Classifying children for sports participation based upon anthropometric measurement. Eur J Sport Sci. 2002:2(3):1-13.

39. Baker J, Janning C, Wong H, Cobley S, Schorer J. Variations in relative age effects in individual sports: skiing, figure skating and gymnastics. Eur J Sport Sci. 2014;14(Suppl 1):S183-90.

40. Costa AM, Marques MC, Louro H, Ferreira SS, Marinho DA. The relative age effect among elite youth competitive swimmers. Eur J Sport Sci. 2013;13(5): 437-44.

41. Medic N, Young BW, Starkes JL, Weir PL, Grove JR. Gender, age, and sport differences in relative age effects among US Masters swimming and track and field athletes. J Sports Sci. 2009:27(14):1535-44.

42. Delorme N, Raspaud M. Is there an influence of relative age on participation in non-physical sports activities? The example of shooting sports. J Sports Sci. 2009;27(10):1035-42

43. Cobley S, Baker J, Wattie N, McKenna J. Annual age-grouping and athlete development: a meta-analytical review of relative age effects in sport. Sports Med (Auckland, NZ). 2009:39(3):235-56.

44. Barnsley $\mathrm{RH}$, Thompson AH, Legault P. Family planning: football style. the relative age effect in football. Int Rev Sociol Sport. 1992;27(1):77-87.

45. Lemez S, MacMahon C, Weir P. Relative Age Effects in women's rugby union from developmental leagues to World Cup tournaments. Res Q Exerc Sport. 2016;87(1):59-67. 
46. Delorme N, Champely S. Relative age effect and chi-squared statistics. Int Rev Sociol Sport. 2013;50(6):740-6.

47. Kim H-Y. Statistical notes for clinical researchers: chi-squared test and Fisher's exact test. Restor Dent Endod. 2017:42(2):152-5.

48. Wattie N, Schorer J, Baker J. The relative age effect in sport: a developmental systems model. Sports Med (Auckland, NZ). 2015:45(1):83-94.

49. Hancock DJ, Ste-Marie DM, Young BW. Coach selections and the relative age effect in male youth ice hockey. Res Q Exerc Sport. 2013;84(1):126-30.

50. Bedard K, Dhuey E. The persistence of early childhood maturity: international evidence of long-run age effects*. Q J Econ. 2006;121(4):1437-72.

51. Muller $L$, Hildebrandt $C$, Schnitzer $M$, Raschner $C$. The role of a relative age effect in the 12th Winter European Youth Olympic Festival in 2015. Percept Mot Skills. 2016;122(2):701-18.

52. van Rossum $J H$. Relative age effect revisited: findings from the dance domain. Percept Mot Skills. 2006;102(2):302-8.

53. Hancock DJ, Starkes JL, Ste-Marie DM. The relative age effect in female gymnastics: a flip-flop phenomenon; 2015.

54. Bjerke $\varnothing$, Lorås $H$, Pedersen AV. Variations of the relative age effect within and across groups in elite alpine skiing. Comprehensive Psychol. 2016;5: 2165222816648077.

55. Sedano S, Vaeyens R, Redondo JC. The relative age effect in Spanish female soccer players. influence of the competitive level and a playing position. J Hum Kinetics. 2015:46:129-37.

56. Raschner $C$, Müller $L$, Hildebrandt $C$. The role of a relative age effect in the first winter Youth Olympic Games in 2012. Br J Sports Med. 2012;46(15):1038-43.

57. Davison KK, Werder JL, Trost SG, Baker BL, Birch LL. Why are early maturing girls less active? Links between pubertal development, psychological wellbeing, and physical activity among girls at ages 11 and 13. Soc Sci Med. 2007;64(12):2391-404.

58. Shakib S. Female basketball participation:negotiating the conflation of peer status and gender status from childhood through puberty. Am Behav Sci. 2003:46(10):1405-22

59. Barnsley RH. Birthdaye and perfromance: the relative age effect. In: Annual Meeting of the Canadian Society for the Study of Education. Ontario, Canada: Windsor; 1988

60. Jayanthi N, Pinkham C, Dugas L, Patrick B, Labella C. Sports specialization in young athletes: evidence-based recommendations. Sports Health. 2013;5(3):251-7.

61. Boccia G, Brustio PR, Moisè P, Franceschi A, La Torre A, Schena F, et al. Elite national athletes reach their peak performance later than non-elite in sprints and throwing events. J Sci Med Sport. 2019;22(3):342-7.

62. Gibbs BG, Jarvis JA, Dufur MJ. The rise of the underdog? The relative age effect reversal among Canadian-born NHL hockey players: a reply to Nolan and Howell. Int Rev Sociol Sport. 2011;47(5):644-9.

63. Cumming SP, Searle C, Hemsley JK, Haswell F, Edwards H, Scott S, et al. Biological maturation, relative age and self-regulation in male professional academy soccer players: a test of the underdog hypothesis. Psychol Sport Exerc. 2018;39:147-53.

64. Delorme N, Chalabaev A, Raspaud M. Relative age is associated with sport dropout: evidence from youth categories of French basketball. Scand J Med Sci Sports. 2011;21(1):120-8.

65. Engström L-M. Who is physically active? Cultural capital and sports participation from adolescence to middle age-a 38-year follow-up study. Phys Educ Sport Pedagog. 2008;13(4):319-43.

66. Nolan JE, Howel G. Hockey success and birth date: the relative age effect revisited. Int Rev Sociol Sport. 2010;45(4):507-12.

67. Vella SA, Cliff DP, Magee CA, Okely AD. Associations between sports participation and psychological difficulties during childhood: a two-year follow up. J Sci Med Sport. 2015;18(3):304-9.

68. Martindale RJJ, Collins D, Abraham A. Effective talent development: the elite coach perspective in UK sport. J Appl Sport Psychol. 2007;19(2):187-206.

69. Moesch K, Elbe AM, Hauge ML, Wikman JM. Late specialization: the key to success in centimeters, grams, or seconds (cgs) sports. Scand J Med Sci Sports. 2011;21(6):e282-90.

70. Williams AM, Reilly T. Talent identification and development in soccer. J Sports Sci. 2000;18(9):657-67.

71. Vaeyens R, Philippaerts RM, Malina RM. The relative age effect in soccer: a match-related perspective. J Sports Sci. 2005;23(7):747-56.

72. Feise RJ. Do multiple outcome measures require $P$ value adjustment? BMC Med Res Methodol. 2002;2:8.

73. Althouse AD. Adjust for multiple comparisons? It's not that simple. Ann Thorac Surg. 2016;101(5):1644-5.

\section{Publisher's Note}

Springer Nature remains neutral with regard to jurisdictional claims in published maps and institutional affiliations.

\section{Submit your manuscript to a SpringerOpen ${ }^{\circ}$ journal and benefit from:}

- Convenient online submission

- Rigorous peer review

- Open access: articles freely available online

- High visibility within the field

- Retaining the copyright to your article

Submit your next manuscript at $\boldsymbol{\nabla}$ springeropen.com 